\title{
Habitat preference, movements and growth of giant mottled eels, Anguilla marmorata, in a small subtropical Amami- Oshima Island river
}

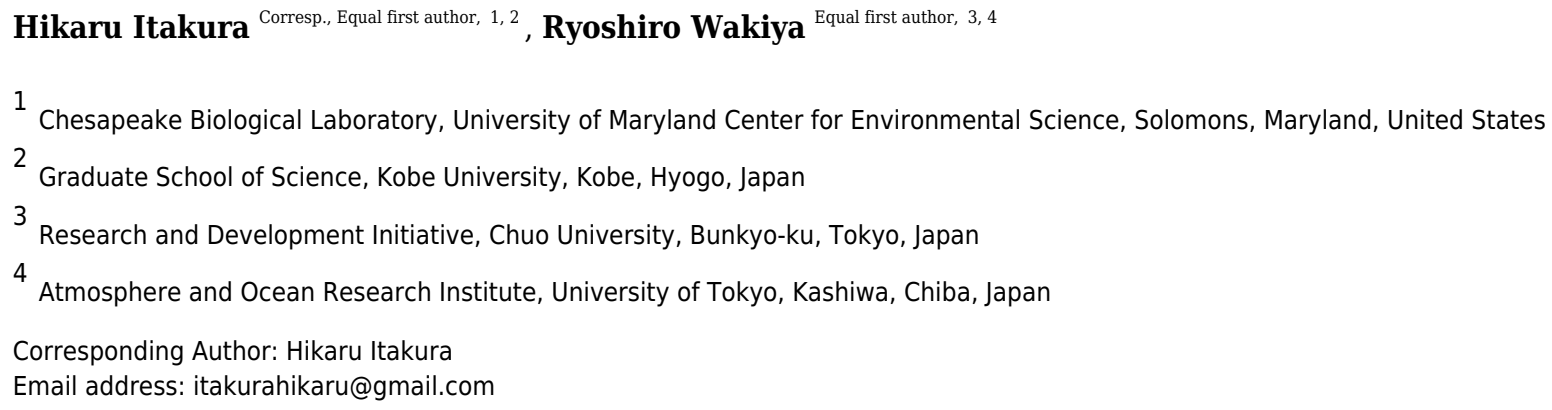

Although anguillid eel populations have decreased remarkably in recent decades, few detailed ecological studies have been conducted on tropical eels such as the giant mottled eel whose range extends across the whole Indo-Pacific. This species was studied throughout the entire $0.5 \mathrm{~km}$ mainstem reaches of Oganeku River on the subtropical Amami-Oshima Island of Japan over a two-year period using 4 sampling periods to understand its habitat preference, early life-stage dispersal process, movements, and annual growth using a mark-recapture experiment conducted with quantitative electrofishing. A total of 396 juvenile growth-phase $A$. marmorata eels were caught and tagged, with 48 individuals being recaptured at least once. Their density irrespective of size of eels was most strongly determined by distance from the river mouth, followed by riverbank type according to random forest models. Eel density decreased with increasing distance from the freshwater tidal limit located about 100-150 m from the river mouth. Eels preferred vegetated riverbanks, while they avoided those of concrete and sand. The density of small eels (total length: TL $<240 \mathrm{~mm}$ ) was also associated with depth and velocity, with small eels tending to prefer riffle or run habitats. In contrast, large eels ( $T L \geq$ $240 \mathrm{~mm}$ ) were found in habitats of any depth and velocity. The TL of eels had a minimum peak at around the tidal limit, and it increased with increasing distance from the tidal limit. The observed density and size gradients of eels in relation to the distance from the river mouth suggested that $A$. marmorata initially recruited to freshwater tidal limit areas and then dispersed in both downstream and upstream directions. The growth rate of eels varied greatly among individuals that were at large for various periods of time and ranged from 0 to $163.2 \mathrm{~mm} /$ year (mean \pm SD of $31.8 \pm 31.0 \mathrm{~mm} /$ year). Of the recaptured eels, $52.1 \%$ were recaptured in a section that was different from the original capture section, 
and their mean \pm SD distance travelled was $46.5 \pm 72.5 \mathrm{~m}$ (median $=20 \mathrm{~m}$ ). $47.9 \%$ of the eels were recaptured from the original section of capture (i.e., $<10 \mathrm{~m}$ distances travelled), suggesting that they had strong fidelity to specific habitats with limited movements. The distance travelled of eels that had moved was greater for small eels (range $=10-380 \mathrm{~m}$; mean $\pm S D=84.4 \pm 121.9 \mathrm{~m}$ ) than large individuals (range $=10-120 \mathrm{~m}$; mean $\pm \mathrm{SD}=$ $30.9 \pm 31.0 \mathrm{~m}$ ), which indicates that the mobility of the eels declines as they grow. This is the first clear detailed documentation of the spatial distribution, growth, and movements of tropical eels in a small river system in relation to environmental conditions that provides an example of how future studies can be conducted in other areas to understand how conservation efforts can be most efficiently targeted for maximum success. 
1

2

\section{Habitat preference, movements and growth of Giant mottled eels, Anguilla} marmorata, in a small subtropical Amami-Oshima Island river

Hikaru Itakura ${ }^{1,2^{*}}$, and Ryoshiro Wakiya ${ }^{3,4^{*}}$

\section{Solomons, Maryland, USA}

${ }^{1}$ University of Maryland Center for Environmental Science, Chesapeake Biological Laboratory,

${ }^{2}$ Graduate School of Science, Kobe University, Kobe, Hyogo, Japan

${ }^{3}$ Research and Development Initiative, Chuo University, Bunkyo-ku, Tokyo, Japan

${ }^{4}$ Present address: Atmosphere and Ocean Research Institute, University of Tokyo, Kashiwa, Chiba, Japan

* Both authors contributed equally to this work.

Corresponding Author:

Hikaru Itakura

146 Williams St., Solomons, MD, 20688, USA.

Email address: itakurahikaru@gmail.com 


\section{Abstract}

35 Although anguillid eel populations have decreased remarkably in recent decades, few detailed ecological studies have been conducted on tropical eels such as the giant mottled eel whose range extends across the whole Indo-Pacific. This species was studied throughout the entire 0.5 $\mathrm{km}$ mainstem reaches of Oganeku River on the subtropical Amami-Oshima Island of Japan over a two-year period using 4 sampling periods to understand its habitat preference, early life-stage dispersal process, movements, and annual growth using a mark-recapture experiment conducted with quantitative electrofishing. A total of 396 juvenile growth-phase $A$. marmorata eels were caught and tagged, with 48 individuals being recaptured at least once. Their density irrespective of size of eels was most strongly determined by distance from the river mouth, followed by riverbank type according to random forest models. Eel density decreased with increasing distance from the freshwater tidal limit located about 100-150 m from the river mouth. Eels preferred vegetated riverbanks, while they avoided those of concrete and sand. The density of small eels (total length: TL $<240 \mathrm{~mm}$ ) was also associated with depth and velocity, with small eels tending to prefer riffle or run habitats. In contrast, large eels (TL $\geq 240 \mathrm{~mm}$ ) were found in habitats of any depth and velocity. The TL of eels had a minimum peak at around the tidal limit, and it increased with increasing distance from the tidal limit. The observed density and size gradients of eels in relation to the distance from the river mouth suggested that $A$. marmorata initially recruited to freshwater tidal limit areas and then dispersed in both downstream and upstream directions. The growth rate of eels varied greatly among individuals that were at large for various periods of time and ranged from 0 to $163.2 \mathrm{~mm} /$ year (mean $\pm \mathrm{SD}$ of $31.8 \pm 31.0$ $\mathrm{mm} /$ year). Of the recaptured eels, $52.1 \%$ were recaptured in a section that was different from the original capture section, and their mean $\pm \mathrm{SD}$ distance travelled was $46.5 \pm 72.5 \mathrm{~m}$ (median $=20$ $\mathrm{m}) .47 .9 \%$ of the eels were recaptured from the original section of capture (i.e., $<10 \mathrm{~m}$ distances travelled), suggesting that they had strong fidelity to specific habitats with limited movements. 
70 Subjects Ecology, Anguillid Eels

71 Keywords Anguilla marmorata, dispersal process, growth rate, habitat preference, movement, 72 mark-recapture experiment 


\section{Introduction}

The eels of the genus Anguilla comprise 16 species of catadromous fishes that undertake largescale oceanic migrations between their offshore spawning areas and growth habitats in continental waters during their life histories. Populations of anguillid eels are distributed throughout much of the world from tropical to temperate regions that include more than 150 countries (Jacoby et al., 2015). Ten species are distributed in tropical regions (i.e., tropical eels), whereas the remaining six species are distributed in temperate regions (i.e., temperate eels). Anguillid eels have ecological, commercial, and cultural importance in many regions (Jacoby et al., 2015) and are increasingly considered as important representative species for freshwater biodiversity conservation efforts (Itakura et al., 2020a). Because of population declines, 10 of the 16 anguillid eel species ( 3 of which are subdivided into subspecies) are listed as "Threatened" or "Nearly Threatened" in the International Union for Conservation of Nature (IUCN) Red List of Threatened Species (IUCN, 2019). Although, the northern hemisphere temperate anguillids have shown well-documented declines, some tropical eels are also of concern for conservation even though their freshwater ecology has not been studied and they are of lower economic commercial importance than the more extensively studied temperate species (Jacoby et al., 2015). Thus, ecological knowledge about tropical eels is clearly essential for the conservation and management of anguillid eels in the Indo-Pacific.

One of the tropical eels, the giant mottled eel, A. marmorata, is the most widespread anguillid species in the world, because it is distributed in the Indian Ocean, and across the IndoPacific to French Polynesia in the South Pacific Ocean (Ege, 1939; Watanabe, Aoyama \& Tsukamoto, 2004). The species has multiple genetically distinct populations (Minegishi, Aoyama \& Tsukamoto, 2008), one of which spawns in the North Equatorial Current region of the western North Pacific Ocean, where the Japanese eel, A. japonica, spawns (Kuroki et al., 2009; Tsukamoto et al., 2011). Because of a recent increase in demand for A. marmorata as a fisheries/aquaculture replacement for temperate eels, especially in East Asia (Gollock et al., 2018), understanding the ecology of $A$. marmorata is particularly important.

Ecological aspects of growth-phase anguillid eels have been extensively studied in temperate eels such as the American eels (A. rostrata), European eels (A. anguilla), and $A$. japonica. After larval development and migration in the open ocean, the leptocephalus larvae of anguillid eels metamorphose into glass eels (early juvenile phase) that enter rivers. Glass eels appear to initially accumulate at the freshwater tidal limit of estuaries, and then disperse in both upstream and downstream directions (Haro \& Krueger, 1991; Edeline et al., 2007; Kaifu et al., 2010; Wakiya et al., 2019). They then settle and spend their growth phase in a variety of habitats ranging from saline bays or brackish estuaries to rivers all the way to upland headwaters, and they also live in lakes (Moriarty, 2003). While small eels exhibit dispersal or movement 
behaviors (Laffaille, Acou \& Guillouët, 2005; Imbert et al., 2010), large individuals mostly display sedentary behavior with limited movements and small home ranges (Gunning \& Shoop, 1962; Parker, 1995; Jellyman \& Sykes, 2003; Ovidio et al., 2013; Itakura et al., 2017). Some individuals however, are increasingly realized to exhibit habitat shifts or seasonal movements between the different habitats (Jessop et al., 2002; Daverat et al., 2006; Yokouchi et al., 2012; Béguer-Pon et al., 2015).

Many studies have reported that the abundance of eels in rivers decline with increasing distance from the tidal limit of estuaries (Ibbotson et al., 2002; Aprahamian et al., 2007; Costa et al., 2008; Kaifu et al., 2010; Wakiya et al., 2019). Riverine distribution of eels can be also affected by other environmental factors in microhabitats such as depth, velocity, sediment, aquatic vegetation, riverbank conditions, effects of which can differ depending on the body size of eels (Glova, Jellyman \& Bonnett, 1998; Laffaille et al., 2003; Kume et al., 2019). These types of environmental factors have the potential to influence the distribution of A. marmorata.

The basic habitat use patterns of tropical eels has been studied recently in a few locations where qualitative sampling or otolith microelement analysis were used. Several studies have found that although A. marmorata tends to live in freshwater areas rather than in brackish and marine habitats (Shiao et al., 2003; Nguyen, Tsukamoto \& Lokman, 2018; Hsu, Chen \& Han, 2019), the species can occupy a broad range of habitats from brackish estuaries to upland headwaters (Arai \& Chino, 2018; Hagihara et al., 2018a; Wakiya, Itakura \& Kaifu, 2019; Kumai, Tsukamoto \& Kuroki, 2020). There are often sympatries of multiple eel species in tropical rivers that appear to affect the patterns of habitat use among the species presumably to reduce interspecific competition (Marquet \& Galzin, 1991; Arai \& Abdul Kadir, 2017; Hagihara et al., 2018a), and sympatries of temperate and tropical eels also occur in subtropical regions of their distribution ranges (Shiao et al., 2003; Hsu, Chen \& Han, 2019; Itakura et al., 2020b). In rivers where a single eel species such as $A$. marmorata is highly dominant among anguillid species, it is found throughout the river network (Robinet et al., 2007; Itakura et al., 2019; Wakiya, Itakura \& Kaifu, 2019).

The growth rate (GR) of anguillid eels is another key aspect of their ecology that reflects many characteristics of the environments where they live. It has been intensively studied for temperate eels (e.g., Vøllestad, 1992; Morrison \& Secor, 2003; Daverat \& Tomás, 2006; Yokouchi et al., 2008), and GR was recently studied for tropical eels as well (Hagihara et al., 2018b; Wakiya, Itakura \& Kaifu, 2019; Kumai, Tsukamoto \& Kuroki, 2020). There is considerable intra-interspecific variation in the annual GR of eels that is related to their latitudinally expanded distributional regions (Hagihara et al., 2018b) and the different environments of the wide-range of continental habitats where eels are present (Morrison \& Secor, 2003; Yokouchi et al., 2008). Eel GR also varies substantially among different ages, 
145 years, and individuals (Yokouchi \& Daverat, 2013). The annual GR of eels has usually been 146 calculated by dividing the body length at capture by age that is estimated based on otolith annual 147 rings after the eels recruit as glass eels, but this method probably overlooks extremely low or 148 high GRs due to inconsistent ring deposition, which would not reflect the actual diversity the GR 149 of eels.

Therefore, ideally, the actual increase of body length during a known period of time of individual eels should be directly measured by mark-recapture experiments, which will provide a

152

153

154

155

156

157

158

159

160

161

162

163

164

165

166

167

168

169

170

171

172

173

174

175

176

177

178

179

180 more precise understanding of their growth strategies. Our objective was to conduct a comprehensive survey and mark-recapture experiment for two years in a small subtropical island river to understand the habitat preference, early life-stage dispersal, movement, and growth of giant mottled eels on Amami-Oshima Island, Japan. Anguilla marmorata is clearly the dominant anguillid species throughout the rivers in this island (Wakiya, Itakura \& Kaifu, 2019; Itakura et al., 2020b,a), thus this island offers suitable study sites for a case study to investigate their ecology in small rivers that have minimal interspecific competition.

\section{Materials and Methods}

\section{Study area and sampling}

This study was conducted in the Oganeku River on Amami-Oshima Island, Kagoshima Prefecture, Japan (Fig. 1; 28²1'42.2"N 129 21'03.4"E). Amami-Oshima Island is located between the southern mainland of Japan and Okinawa Island adjacent to the western North Pacific Ocean and next to the Kuroshio Current that is one of the strongest western boundary currents. This is the second largest island in the Nansei Islands (Okinawa is the largest) in terms of area $\left(712.35 \mathrm{~km}^{2}\right)$. The climate of this island is characterized by a warm and wet climate with an average annual temperature of $21.6^{\circ} \mathrm{C}$ (monthly range: $14.8-28.7^{\circ} \mathrm{C}$ ), with a peak in July and annual precipitation of $2837.7 \mathrm{~mm}$ (monthly range: 156.9-410.3 mm) with a peak in June (1981-2010 data of the Japan Meteorological Agency, https://www.jma.go.jp/jma/index.html).

The study river is approximately $0.5 \mathrm{~km}$ in length, and flows through agricultural and forest lands (Fig. 2). The elevation of the river increases dramatically to $>10 \mathrm{~m}$ from around the $320 \mathrm{~m}$ area from the river mouth where the riverscape transitioned to higher-gradient upstream environments. There is a waterfall $>10 \mathrm{~m}$ height at $520 \mathrm{~m}$ from the river mouth (elevation $=50$ $\mathrm{m})$. Although some eels might be able to climb the waterfall, we surveyed from the river mouth to the waterfall, because we were not able to access areas above the waterfall. Because the river width around the waterfall is much narrower $(<1 \mathrm{~m})$, the river flow may originate not far above the waterfall. Thus, our surveyed area was considered to cover almost all of the mainstem of the river. The width of the river was $3.2 \pm 2.0 \mathrm{~m}$ (mean $\pm \mathrm{SD}$; range: $0.5-8.4 \mathrm{~m}$ ), and the depth was $22.2 \pm 16.7 \mathrm{~cm}$ (range: $3-75 \mathrm{~cm}$ ). The freshwater tidal limit of the river was observed during our 
181 surveys to be located at about 100-150 m from the river mouth based on tidally influenced 182 increases in water depth during high tides. The freshwater areas of this island are dominated by 183 diadromous species (Itakura et al., 2020a). A total of 33 species (24 fishes and 9 crustaceans) was identified in the study river during the sampling surveys, all of which were diadromous species (Table S1). A. marmorata was the dominant fish species in terms of both abundance and biomass in the river. This island is near the northern limit of the distribution range of $A$. marmorata (Jacoby \& Gollock, 2014), but some eels also recruit to areas farther north in mainland Japan (Mizuno \& Nagasawa, 2010).

We chose this river because (1) such a small stream allowed us to conduct quantitative sampling throughout all the main reaches of a river using electrofishing, and (2) there are no artificial migration barriers (e.g., weirs and dams) that can impede eel movement in the river, thus providing a good model system to examine their ecology without the effects of barriers. A recent study conducted in other rivers on this island showed that the density of $A$. marmorata was strongly negatively associated with cumulative height of the barriers (Itakura et al., 2020a).

Quantitative sampling for eels was carried out a total of four times during August and November 2016, July 2017, and September 2018 (25 month period). We captured anguillid eels over almost the entire area of the river from the river mouth to the uppermost reaches of the river (below the waterfall) using a back-pack electroshocker (LR-20B, Smith-Root, Inc., Vancouver, WA, USA) and hand nets by two people during daytime. Each $10 \mathrm{~m}$ interval of the river channel was regarded as a sampling section (defined by the downstream border), and each section was defined by the distance from the river month. Each section was sampled by moving side to side starting from the downstream direction moving upstream, with each section being marked with wooden stakes along the riverbank. Sampling was performed during low tides at sections below the freshwater tidal limit of the river in order to avoid the effect of salinity on the efficiency of electrofishing. As a result, we confirmed the sections were freshwater during low tides. Captured eels were held in river water until they were anaesthetized with 10\% eugenol solution (FA100; DS Pharma Animal Health Co., Ltd. Japan). Each specimen was identified morphologically following Watanabe, Aoyama \& Tsukamoto, (2004), and their growth stage was confirmed based on the color of its body and pectoral fins following previous studies (Okamura et al., 2007; Hagihara et al., 2012). One sexually-maturing A. marmorata (580 $\mathrm{mm}$ in TL) was collected at the $290 \mathrm{~m}$ section on September 2018 and this was excluded from this study, because it might have already started its early migration to the ocean to spawn.

The TL and body weight (BW) of each eel were measured to the nearest $1 \mathrm{~mm}$ and $0.1 \mathrm{~g}$, respectively, and then they were individually tagged and released back into the capture sites after they fully recovered from the anaesthesia. Each eel was tagged using different methods depending on its body weight. Large eels with $\mathrm{BW} \geq 10 \mathrm{~g}$ were individually tagged by injecting 
217 a passive integrated transponder (PIT tag; BIO8.B03, Biomark, ID, USA; 1.4 mm diameter) tags

218 into the abdominal cavity (228 eels), while small ones with $\mathrm{BW}<10 \mathrm{~g}$ were tagged using

219 injected visible implant elastomer (VIE tag; Northwest Marine technology, WA, USA) tags (105

220 eels). The small eels were individually distinguished based on a combination of different

221 elastomer colors and the area of the body where they were injected (i.e., jaw, eye, and near anus).

222 The sampling was conducted under the guidance and with the permission of the Fisheries

223 Adjustment Rules of Kagoshima Prefecture (approval number: 2006-5 for 2016 and 2006-10 for

2242017 and 2018).

225 Environmental conditions at each sampling section were measured and recorded

226 immediately after the sampling in August 2016, which was during typical water flow conditions

227 compared to the other sampling periods. The depth and water velocity were measured at the

228 center of the river in the middle of each $10 \mathrm{~m}$ section, while the river width was measured at the

229 downstream border of each section. The sediment was categorised into six types: mud, sand,

230 gravel, boulder, concrete or bedrock, and mud and boulder. The riverbank was categorised into

231 seven types by the combination of left and right banks: sand, boulder, vegetation, concrete,

232 concrete and gravel, concrete and vegetation, and concrete and boulder (i.e., 2 classifications per

233 section).

234

235

Growth and movement

236

The growth rate (GR; mm/year) of each recaptured eel was calculated as: $G R=$

237

$\left(\left(T L_{2}-T L_{1}\right) /\left(t_{2}-t_{1}\right)\right) \times 365$ where $T L_{1}$ and $T L_{2}$ are TL of eels at $t_{1}$ (date at capture) and $t_{2}$

238

(date at recapture).

The distance travelled $(\mathrm{m})$ of recaptured eels was calculated as distance between the capture and recapture sections. As we did not document where eels were captured within each section, eel movement was quantified only when an eel was recaptured in a section that is different from the original capture section. The eel movement distance was regarded as $0 \mathrm{~m}$ (absence of movement, i.e., travel distance $<10 \mathrm{~m}$ ) when they were recaptured in the same section where they were originally captured, whereas it was regarded as a $10 \mathrm{~m}$ movement when they were recaptured in an adjacent section. Technically, this means that the eel movements between adjacent sections could have ranged from 0 (on the section borderline) to $20 \mathrm{~m}$ (on opposite borderlines). Thus, for analyzing relationships between eel TL and presence of movement, we used both 10 and 20 m distances for adjacent-section movements.

\section{Data analysis}

All statistical analyses were performed with $\mathrm{R}$ 3.6.0. To evaluate the riverine distribution of TL 
252 of eels, we used a generalized additive model (GAM; gam function in the $m g c v$ ) (Wood, 2019), 253 which included TL as a response variable (gaussian distribution with an identity-link function), 254 and distance from the river mouth as a predictor variable. To assess how the eel movement

255 changed as the eels grew, we used a generalized linear model (GLM), which included either the presence or absence of eel movement (i.e., 1 or 0 ) as a response variable (binomial distribution with a logit-link function), and TL as a predictor variable. The relationship between TL at initial capture before each recapture and distance travelled of recaptured eels was also evaluated using a GLM with a negative binomial distribution and a log-link function. In addition, the effects of TL class (small and large eels), TL at initial capture before each recapture, the study period (i.e., duration between capture and recapture), the eel movement (i.e., distance travelled of $0 \mathrm{~m},<80$ $\mathrm{m}, \geq 80 \mathrm{~m}$ ), and the sampling section from the river mouth on the GR of recaptured eels were assessed using a GLM with a gaussian distribution and an identity-link function. The GR was $\log$-transformed by adding 1 , to meet the assumption of normality of the residuals. In the growth model, variable selections were performed according to Akaike's information criterion (AIC) using dredge in the package MuMIn (Bartoń, 2019). Moreover, the proportion of eels that moved and the distance travelled by eels were compared between small and large eels using the Fisher's exact test and the Exact Wilcoxon-Mann-Whitney test, respectively. TL of eels at initial capture before each recapture was also compared between eels that moved and those that did not move using the Exact Wilcoxon-Mann-Whitney test. We defined eels $<240 \mathrm{~mm}$ TL as small eels, and eels $\geq 240 \mathrm{~mm}$ TL as large eels, following previous studies for growth-phase European and Japanese eels that reported that the mobility of eels can change at around $240 \mathrm{~mm}$ TL (Imbert et al., 2010; Wakiya, Kaifu \& Mochioka, 2016), because there is no information on the TLmobility relationship for $A$. marmorata.

To evaluate the effects of environmental factors on the density of eels, we used the permutation-based random forest (RF) machine learning algorithm (Hapfelmeier \& Ulm, 2013). The RF is an ensemble learning algorithm that builds a predictive regression model (forests) by taking an average from outputs of a large number of decision tree models (Breiman, 2001). We selected the RF algorithm, because RF (1) does not require normality or independence of the variables, (2) is able to handle non-linear relationships well, (3) is not prone to overfitting by averaging a large number of decision tree models (Breiman, 2001), (4) fairly evaluates the relative importance between continuous and categorical variables without bias (Strobl et al., 2008), and (5) can perform variable selection and assess the relative importance among highly correlated variables (Nicodemus et al., 2010; Bergmann et al., 2017).

The density of $A$. marmorata in each sampling section was calculated by dividing the number of captured eels by area of the study section $\left(\mathrm{m}^{2}\right)$. The densities of eels of three size classes were used as response variables: all eels, small eels (TL $<240 \mathrm{~mm})$, and large eels 
288 ( $T L \geq 240 \mathrm{~mm}$ ). The environmental factors including depth, water velocity, distance from the 289 river mouth, sediment, and riverbank were used as predictor variables. We used the RF algorithm 290 for performing multiple regressions for variable selection (Hapfelmeier \& Ulm, 2013; Ryo et al., 291 2018). The RF algorithm with variable selection by Hapfelmeier \& Ulm (2013) first performs a 292 multiple regression using all predictor variables to estimate a statistical significance for each variable. Then, the RF algorithm performs a multiple regression using only significant variables to construct the final RF model and to estimate a relative importance score for each variable (see Hapfelmeier \& Ulm, 2013 and Ryo et al., 2018 for more detail about the RF algorithm). We set the significance level to 0.01 with Bonferroni correction for the number of predictor variables following Ryo et al. (2018). The relative importance score of each variable was quantified by evaluating how much model accuracy can decrease when the model removes the focal variable (Breiman, 2001). The modelled relationships between the predictor variables and each response variable were visualized using partial dependence plots, which represent the marginal effect of a particular response variable on the modelled function after marginalizing out the effects of all the other variables. The procedure calculates a partial dependence score that indicates the relative extent of the response variable. In our case, the higher the score, the higher the density of eels. Model performance was evaluated based on explanatory and predictive powers $\left(R^{2}\right)$. Explanatory power was evaluated based on the coefficient of determination by comparing observed and fitted values as explained variance. In contrast, prediction power (validation accuracy) is a metric to estimate an expected model performance for prediction when a new dataset is analyzed. Prediction power was also evaluated based on the coefficient of determination using $1 / 3$ of the samples that were not used in the tree construction, following the out-of-bag technique (Breiman, 1996).

We used the R script available in Ryo et al. (2018), which was modified from the script by Hapfelmeier \& Ulm (2013). The script is based on ctree and cforest functions in the package party (Strobl, Hothorn \& Zeileis, 2009) for RF modeling, cforeststats and postResample functions in the package caret (Kuhn et al., 2020) for evaluating model performance, and the generatePartialDependenceData function in the package $m l r$ (Bischl et al., 2020) for partial dependence plots. All parameters in the functions were set to defaults.

\section{Results}

\section{Number of collected eels, size and density}

A total of 396 growth-phase A. marmorata were collected in this study (this includes number of recaptured eels). Eels were collected in each of the 4 sampling times of August 2016 (152 eels), November 2016 (80 eels), July 2017 (60 eels), and September 2018 (104 eels). The size of all captured eels ranged from 62 to $770 \mathrm{~mm}$ TL with a mean \pm SD of $336.8 \pm 153.0 \mathrm{~mm}$ (Fig. 3) and 
324 their BW ranged from 0.5 to $1219.0 \mathrm{~g}$ with a mean $\pm \mathrm{SD}$ of $136.7 \pm 167.5 \mathrm{~g}$. The number of 325 collected eels per sampling section ranged from 0 to 19 individuals, with the greatest single-

326 section catch $(n=19)$ consisting of only large eels $(T L \geq 240 \mathrm{~mm}, 431.1 \pm 89.4 \mathrm{~mm}, 246-590$ $\mathrm{mm}$ ) that were collected at a section $60 \mathrm{~m}$ from the river mouth that consisted of concrete and boulder riverbanks and mud sediment (Fig. 4). The density of eels in each section (when more than 1 individual was collected) ranged from 0.01 to 0.69 eels $\mathrm{m}^{-2}$, with a mean $\pm \mathrm{SD}$ of $0.15 \pm$ 0.13 eels $\mathrm{m}^{-2}$ (Fig. S1A). Of the collected eels, 48 individuals were recaptured at least once (39 PIT tagged eels, 9 elastomer tagged; 8 recaptures 2-3 times), and thus a total of 339 unique individuals were collected in this study. We obtained 57 records on movement events and 57 records for annual GR of the 48 recaptured eels. The TL of these eels at first-capture was $381.3 \pm$ $131.0 \mathrm{~mm}$, with a range from 105 to $656 \mathrm{~mm}$, and those at recapture were $408.1 \pm 135.8 \mathrm{~mm}$ in TL, with a range from 139 to $770 \mathrm{~mm}$.

A total of seven A. japonica were collected at 60, 80, 90, 100, 150, 170, and $280 \mathrm{~m}$ sections where the sediment consisted of gravel and riverbanks consisted of boulders or vegetation, and water velocities were $<40 \mathrm{~cm}^{-2}$ (Fig. 4). Their TL was $364.0 \pm 161.7 \mathrm{~mm}$, with a range from 126.0 to $541.0 \mathrm{~mm}$ (Fig. 4C). The captured A. japonica were omitted from the analyses of this study.

\section{Size distribution}

Almost all small eels ( $\mathrm{TL}<240 \mathrm{~mm}$ ) were collected in the sections that were about 100-300 $\mathrm{m}$ from the river mouth, and more of the smallest eels $<100 \mathrm{~mm}$ TL were collected in the 100-200 $\mathrm{m}$ sections (Fig. 4C). Conversely, large eels ( $\mathrm{TL} \geq 240 \mathrm{~mm}$ ) were collected throughout the river (Fig. 4C), although they were not evenly distributed. Large eels were caught in $82 \%$ of the total sections, but small eels were caught only in $54 \%$ of the total sections. The GAM showed that the TL of $A$. marmorata was significantly associated with distance from the river mouth (Effective d.f. $=8.556$, Reference d.f. $=8.927, F=15.45, p<0.001$; Fig. 4 C). The predicted TL reached a minimum value at around the 100-150 m sections in part due to few large eels being caught there, and it increased with increasing distance upstream because only 3 small eels were caught above $300 \mathrm{~m}$ (Fig. 4C). However, large eels $\geq 240 \mathrm{~mm}$ TL were caught from very near the river mouth to the farthest upstream sections, with the most eels $>600 \mathrm{~mm}$ TL being caught near 300 $\mathrm{m}$ where a wide size range (141-770 $\mathrm{mm}$ TL) was present in an area that was pool and run habitats with gravel or mud sediments and concrete and boulder riverbanks (Fig. 4, Figs. S1A, S1B, S1C).

\section{Habitat preference}

Distance from the river mouth was the most important explanatory variable to predict density of 
360

361

362

eels followed by riverbank type, both of which were selected by the RF models for all three sizeclasses (i.e., all eels, small eels, and large eels) (Fig. 5). Conversely, velocity and depth were only selected by the model for small eels. The explanatory powers ( $R^{2}$ value) were $45.7 \%$, $40.9 \%$, and $32.3 \%$ of the variation in densities of all, small, and large eels, respectively (validation accuracy: $30.3 \%, 23.6 \%$, and $16.4 \%$, respectively).

The density of eels peaked at around 130-200 m sections where both large and small eels were present, and it decreased with increasing distance from the peaks where fewer mostly large eels were found (Fig. 6A). The density of small eels was consistently low at more reaches of the river upstream of the $300 \mathrm{~m}$ section (less than 0.02 eels $\mathrm{m}^{2}$ ), especially considering that only 4 (August 2016), 0 (November 2016), 0 (July 2017), and 3 (September 2018) small eels were caught (Fig. S2). Eels were abundant just below the $310 \mathrm{~m}$ section, which was a pool habitat followed by concrete riverbank and sediment habitats at 320-350 m sections, and then the riverscape greatly changed to high elevation gradient $(>10 \mathrm{~m})$ upstream environments (boulder riverbank and boulder and gravel sediments) at the $360 \mathrm{~m}$ section (Fig. 2, Fig. 4). The density of eels was consistently lower among all three size-classes when riverbanks consisted of concrete and sand, while it was the highest when riverbanks consisted of vegetation, some of which extended into the water where some eels were collected (Figs. 6B, 7D). The density of small eels decreased when water depth was more than $15 \mathrm{~cm}$ (Fig. 6C) and when water velocity was less than $20 \mathrm{~cm}^{-\mathrm{S}}$ (Fig. 6D). In contrast, large individuals were found in a broader range of habitats with any depth and velocity (Figs. 7A, 7B).

Although sediment type was not selected the RF models for all three size-classes as a significant variable, the density of eels appeared to differ among sediment types (Fig. 6C). Eels were rarely found in sediment consisting of concrete and sand, and no large eels were found there. Almost all small eels were found in gravel sediment habitats that were located from $70 \mathrm{~m}$ to $300 \mathrm{~m}$ sections (Figs. 4, 7C), while they were rarely found in other sediment types. Large eels were found in a broader range sediment types with their densities being higher in mud and boulder sediments, and in combinations of habitats (Figs. 4, 7C).

\section{Movements of tagged eels}

Of the recaptured eels, $47.9 \%$ were recaptured from their original section of capture (i.e., distance travelled $<10 \mathrm{~m}$ ) (Figs. 8A, 8B), and the distance travelled of $75.9 \%$ of eels that were recaptured in a section that is different from the original capture section (i.e., distance travelled $\geq$ $10 \mathrm{~m})$ were less than $50 \mathrm{~m}$. Of the observed movement events $(\mathrm{n}=31), 54.8 \%$ of the eels travelled in the upstream direction from the original section of capture (Fig. 8B). The distance travelled of recaptured eels that moved $\geq 10 \mathrm{~m}$ ranged from $10 \mathrm{~m}$ to $380 \mathrm{~m}$ with a mean $\pm \mathrm{SD}$ of $46.5 \pm 72.5 \mathrm{~m}($ median $=20 \mathrm{~m} ; \mathrm{n}=31)$. The distance travelled of recaptured large eels $(\mathrm{TL} \geq 240$ 
396

397

398

399

400

401

402

403

404

405

406

407

$\mathrm{mm}$ ) ranged from $0 \mathrm{~m}$ to $120 \mathrm{~m}$ with a mean $\pm \mathrm{SD}$ of $15.1 \pm 26.5 \mathrm{~m}$ (median $=0 \mathrm{~m} ; \mathrm{n}=45$ ), while that of small eels $(\mathrm{TL}<240 \mathrm{~mm})$ ranged from $0 \mathrm{~m}$ to $380 \mathrm{~m}$ with a mean $\pm \mathrm{SD}$ of $63.3 \pm$ $110.8 \mathrm{~m}$ (median $=20 \mathrm{~m} ; \mathrm{n}=12)$.

The proportion of movements more than $10 \mathrm{~m}$ was higher in small eels $(75.0 \%)$ than in large eels (51.1\%), but there was not a significant difference (Fisher's Exact Test, $P=0.191$ ). The distance travelled of small eels (mean $\pm \mathrm{SD}=84.4 \pm 121.9 \mathrm{~m}$, median $=20$ ) was greater than that of large eels (mean $\pm \mathrm{SD}=30.9 \pm 31.0 \mathrm{~m}$, median $=20)$, but there was not a significant difference (Exact Wilcoxon-Mann-Whitney test, $P=0.262$; Fig. $8 \mathrm{~B}$ ). There were no significant relationships between the probability of occurrence of eel movement and TL at initial capture before each recapture (GLM: $P>0.05$ ), irrespective of the possible distances at which the movement was observed (i.e., 10 and $20 \mathrm{~m}$ ). The distance travelled of eels was significantly negatively related to TL at initial capture (GLM: coefficient $\pm \mathrm{SE}=-0.003 \pm 0.001, \mathrm{t}=-2.376, \mathrm{P}$ $=0.018$ ), however, TL at initial capture was not statistically different between eels that moved and those that did not move (Exact Wilcoxon-Mann-Whitney test, $P=0.138$; Fig. S3A).

\section{Growth rate}

The GR of recaptured eels ranged from 0 to $163.2 \mathrm{~mm} / \mathrm{year}$ with a mean $\pm \mathrm{SD}$ of $31.8 \pm 31.0$ $\mathrm{mm} /$ year (median $=24.1 \mathrm{~mm} /$ year; $\mathrm{n}=57$ ) (Fig. 8C). The best GLM having the lowest AIC value showed that the GR was significantly higher for eels that moved $\geq 80 \mathrm{~m}$ (GLM: coefficient $\pm \mathrm{SE}=1.798 \pm 0.528, t=3.405, P=0.001)$ than for eels that moved $<80 \mathrm{~m}$ (GLM: coefficient \pm $\mathrm{SE}=0.750 \pm 0.320, t=2.344, P=0.023)$, both categories of eels that moved had significantly higher GR than the eels that did not move (Fig. S3B); although it is still unclear whether eels that moved ended up growing faster or faster growing individuals decided to move more. GR also increased with TL at initial capture (GLM: coefficient $\pm \mathrm{SE}=0.004 \pm 0.001, t=3.856, P<$ 0.001; Fig. S4A). The GR of eels was lower for small eels than that of large eels (Fig. S3C) and was different among the study periods (Fig. S4B), but these variables were not selected by the best model. Similarly, the sampling section distance from the river mouth was not selected by the best model for affecting GR. The eels that showed no growth between marking and recapture included five eels that were captured 3 months after tagging, and two eels that were captured after 11 and 25 months (Fig. S4A)

\section{Discussion}

\section{Habitat preference}

The RF models revealed that the distance from the river mouth was consistently the most important variable to explain density of $A$. marmorata irrespective of size of eels. Few small eels were caught in the upstream sections $>300 \mathrm{~m}$ upstream and in sections $<100 \mathrm{~m}$ from the river 
432 mouth where large eels were present. Eels of all sizes were present from 100-300 m. As

433 anguillid eels recruit from the sea to rivers, it has been well known for temperate eels that the

434 density of eels in rivers is strongly related with the distance from the river mouth (Smogor,

435 Angermeier \& Gaylord, 1995; Glova, Jellyman \& Bonnett, 1998; Ibbotson et al., 2002;

436 Yokouchi et al., 2008; Itakura et al., 2019). For tropical eels, the abundance of $A$. marmorata

437 was also significantly related with the distance from the river mouth when the species is highly

438 dominant among anguillid species throughout rivers (Robinet et al., 2007; Itakura et al.,

$4392020 \mathrm{~b}, \mathrm{a})$, which is consistent with our findings. Therefore, the distance from the river mouth is

440 likely one of the most common and important factors that determine the riverine distributions

441 anguillid eel species.

442 The density of small A. marmorata was also negatively or positively related with water

443 depth and velocity, respectively. Higher densities of small eels being present at shallower depths

444 compared to in deeper areas was also found for temperate eels such as A. japonica (Kume et al.,

445 2019), A. anguilla (Laffaille et al., 2003), A. rostrata (Johnson \& Nack, 2013), and A. australis

446 (Glova, Jellyman \& Bonnett, 1998), and higher densities of small eels were also found in faster

447 velocity waters for $A$. anguilla (Laffaille et al., 2003) and A. dieffenbachii (Glova, Jellyman \&

448 Bonnett, 1998). Small A. marmorata, therefore, seem to prefer shallow and fast-velocity waters

449 (i.e., riffle or run, usually gravel or rocky sediments) rather than deep and slow-velocity areas

450 (i.e., pools), although it should be noted that it is likely more difficult to collect small eels using

451 electrofishing in deep areas than shallow areas, which could partly cause the difference of

452 catchability between these areas. The distribution of small A. marmorata was biased toward

453 habitats that consisted of gravel sediment, possibly because all tidal limit areas in the study river

454 where almost all small eels were collected consisted of the gravel sediment. The grain size of

455 gravel as a refuge seems better for small eels than others, and so the riffle or run habitats with

456 gravel may provide suitable refuges and feeding area for small eels. Conversely, such riffle and

457 run habitats with gravel were also present in the upper reaches of the river, but the distribution of

458 small eels was biased toward the lower reaches, suggesting that they prefer such habitats in the

459 lower reaches. Because sediment was not selected by the RF models as an important variable,

460 these results imply that the effect of sediment was masked by the strong effect of distance from

461 the river mouth. As shown by this study and previous studies, the distance from the river mouth

462 strongly contributes to determine eel density, which may mask microhabitat effects, especially

463 when the survey was only conducted in a river that includes one pattern of distribution of habitat

464 variables in relation to the distance from the river mouth. Therefore, further surveys in multiple

465 rivers that have diverse distribution patterns of habitat variables are required to clarify

466 microhabitat effects on eel distribution without the effect of the distance from the river mouth.

467 In contrast with small eels, the density of large A. marmorata was not significantly related

Peer] reviewing PDF | (2020:05:49339:1:2:NEW 10 Sep 2020) 
to the microhabitat environments except for riverbank type. This indicates that the relationship between the microhabitat environments and eel density disappeared as the eels grow. Indeed, large individuals were found in broader habitats with any depth, velocity, and sediment type, and these factors were not selected by the final RF models. A similar finding was found for $A$. japonica in which the density of large eels $\geq 240 \mathrm{~mm}$ TL was not correlated with any depth, velocity, or sediments (Ministry of Environment, 2016). Such size-dependent changes in habitat use has also been reported for other anguillid species: large $A$. dieffenbachii are more uniformly spread across riffle, run, and pool habitats than small ones (Glova, Jellyman \& Bonnett, 1998); A. anguilla progressively shift to deeper habitats as they grow (Laffaille et al., 2003); and small $A$. japonica used habitats near riverbanks, but large ones used habitats both near-riverbank and the center of rivers (Kume et al., 2020). Our results and those of previous studies suggest that eels appear to be able to flexibly use habitats having a variety of environments as they grow, which allow eels to move into and utilize the entire range of continental waters from saline bays, to entire river systems up to the headwaters if there are no obstacles (Moriarty, 2003).

Although $A$. marmorata seem to inhabit any habitat type as they grow, they appeared less likely to prefer habitats where the physical structure of the riverbank or riverbed was artificially altered by concrete. The RF models revealed that riverbank type also consistently contributed to explaining the density of eels as the second most important variable irrespective of size of eels. While the models estimated the highest densities to occur when riverbanks consisted of vegetation, riverbanks consisting of concrete and sand were estimated to have the lowest densities. Moreover, eels were rarely found in sediment areas that consisted of concrete and no large eels were found there. It was reported that abundance of A. japonica was lower in areas that consisted of concrete revetment compared to those with vegetation or mud (Itakura et al., 2015), which corresponds to our findings. Such habitat modifications often result in reduced abundance and diversity of freshwater animals due to loss of structural diversity along riverbanks or riverbeds (Taniguchi, Inoue \& Kawaguchi, 2001; Wolter, 2001). Thus, it is obvious that concrete does not provide suitable habitat for eels or their prey species because it is not possible to find shelter in concrete unless it is highly fractured, which may lead to the somewhat patchy distribution observed in this study. However, the density of eels was higher in sections that the riverbank consisted of concrete with boulders, vegetation, and gravel compared to that of concrete only. These combinations between concrete and the other materials made the density of eels almost identical to that in habitat consisting of vegetation. In addition, with regard to the combination between riverbank and sediment types, some eels were caught in the 110 and $120 \mathrm{~m}$ sections where the riverbank consisted of concrete with other types of sediments, while only one eel was caught in 320-350 m sections where both riverbank and sediment consisted of concrete. These results suggest that the combination-habitats of concrete and other materials may provide 
504

enough refuges for eels to inhabit the river at the current density levels.

However, habitat losses such as shoreline and riverbed modifications might cause higher densities of $A$. marmorata in the more suitable natural habitats by concentrating eels in those habitats. The resulting stronger intraspecific competition may lead to increased mortality or slower growth. A long life (mean $\pm \mathrm{SD}=12.8 \pm 4.9$ years; range $=3-30$ on the study island: Wakiya, Itakura \& Kaifu, 2019) with very slow annual growth, strong site fidelity, and sizedependent habitat preference of $A$. marmorata imply that they may be impacted by the habitat modifications of rivers on small islands such as the Oganeku River. Therefore, it is important to have long-term maintenance of diverse riverine habitats to conserve this eel species.

The TL of $A$. marmorata observed in the study river $(336.8 \pm 153.0 \mathrm{~mm}$ with a range of $62-770 \mathrm{~mm})$ did not clearly differ with that in other rivers on the same island $(385.5 \pm 172.6 \mathrm{~mm}$ with a range of 119-1320 mm; Wakiya, Itakura \& Kaifu, 2019); however, larger eels $>800 \mathrm{~mm}$ in TL were absent in this study. It is well known that $A$. marmorata can frequently grow up to over a meter, but such larger eels are females only (Hagihara et al., 2018b). Wakiya, Itakura \& Kaifu, (2019) reported that males are dominant in other rivers in same island and there were very few larger female eels $>800 \mathrm{~mm}$. Although sex was not identified in this study, the majority of eels caught in the study river seems to be males that can start the spawning migration at $<800$ $\mathrm{mm}$ in TL, which may explain the absence of larger eels (females) there. The absence of the larger eels in the study river might be explained by the lack of much deeper pool waters that are preferred by larger eels, while rivers in Wakiya, Itakura \& Kaifu, (2019) have such deeper waters due to their larger river scale than the study river.

\section{Dispersal process after recruitment}

The distributions of density and TL of $A$. marmorata provided interesting information about the dispersal process of the species after recruitment into the river. Eels that were $<100 \mathrm{~mm}$ TL were mostly found in the sections 100-200 $\mathrm{m}$ from the river mouth where the freshwater tidal limit was located (100-150 m), while small eels $<240 \mathrm{~mm}$ TL were found at a wider range of sections between 100-300 m. The GAM model showed that the TL of eels had a minimum peak at around the tidal limit of the 100-150 m sections, and increased with increasing distance from the tidal limit. Moreover, the RF models revealed that densities of all eels, small eels, and large eels peaked at around the tidal limit, and they decreased with increasing distance from the tidal limit. These density and size gradients of eels in relation to the distance from the river mouth indicate that $A$. marmorata initially recruited to freshwater tidal limit areas after recruitment into the river and then dispersed in both downstream $(<75 \mathrm{~m})$ and upstream directions as they grew. No glass eels and few smaller eels of $A$. marmorata were collected in this study, partly because it is difficult to capture them using electrofishing. Nevertheless, we collected small eels less than 100 
$540 \mathrm{~mm}$ TL with the smallest individual being $62 \mathrm{~mm}$ TL, which would likely be individuals that 541 recruited to the river within the last year. Therefore, A. marmorata arriving from the sea into the 542 river seem to initially settle in the tidal limit area.

This type of dispersal process after recruitment may be common among anguillid eels because similar processes have been reported for temperate eels such as A. anguilla (Edeline et al., 2007; Costa et al., 2008) and A. japonica (Kaifu et al., 2010; Wakiya et al., 2019). Glass eels and the subsequent smaller growth-phase eels are often abundant at the freshwater areas of the upper estuaries (tidal limit) of rivers and their sizes increase with increasing distance from the tidal limit, while their densities peaked at the tidal limit (Haro \& Krueger, 1991;Daverat \& Tomás, 2006; Aprahamian et al., 2007; Edeline et al., 2007; Costa et al., 2008; Kaifu et al., 2010; Wakiya et al., 2019). Conversely, a more homogenous distribution of smaller growth-phase eels was found in an estuary compared to the glass eels (Edeline et al., 2007). These size and density gradients of eels are thought to result from the dispersal behavior of eels, which shows that glass eel arriving from the sea accumulate at the freshwater tidal limit of an estuary and then disperse in both more downstream and upstream directions as they grow. Our first of their kind results for tropical eels are in agreement with these previous studies. The common point between $A$. marmorata in this study and these temperate eel species is that each eel species is highly dominant among anguillid species throughout the rivers in each distributional area. In our study river, only 7 Japanese eels were caught during the 4 sampling periods, so they are clearly not abundant compared to A. marmorata, or most do not survive very long. The dispersal process of A. marmorata shown in this study may change depending on whether sympatries of multiple eel species occur within same watersheds (Marquet \& Galzin, 1991; Shiao et al., 2003; Arai \& Abdul Kadir, 2017; Hagihara et al., 2018a; Hsu, Chen \& Han, 2019). Therefore, future research conducted in regions with sympatries of multiple eel species will help to further understand how these sympatric eel species disperse to each habitat in river systems.

This dispersal behavior might be an adaptive strategy to increase individual fitness by reducing intraspecific competition. The mortality of eels in freshwater may primarily be related to density-dependent factors such as intraspecific competition for resources or predation by eels (Vøllestad \& Jonsson, 1988). Because higher density would lead to stronger intraspecific competition, the eel movements from the tidal limit to both downstream and upstream directions can be regarded as density-dependent dispersal that mitigates the competition (Edeline et al., 2007; Kaifu et al., 2010). Homogenous distribution of smaller growth-phase eels around the tidal limit also suggests density-dependent dispersal (Edeline et al., 2007). As shown in this study, the growth-phase eels after dispersal and subsequent settlement in habitats exhibit strong sedentary behavior and limited movements (Jellyman \& Sykes, 2003; Ovidio et al., 2013; Itakura et al., 2017). Accordingly, the dispersal-related movements may be one of the key elements to mitigate 
576

577

578

579

580

581

582

583

584

585

586

587

588

589

590

591

592

593

594

595

596

597

598

599

600

601

602

603

604

605

606

607

608

609

610

611

the intra-interspecific competitions during their growth stage.

\section{Movements of eels}

The mean distance travelled of the tagged large A. marmorata was $15.1 \pm 26.5 \mathrm{~m}$ (median $=0$

$\mathrm{m}$ ), which is consistent with previous studies for temperate eels showing that most growth-phase anguillid eels have limited movements (Gunning \& Shoop, 1962; Parker, 1995; Jellyman \& Sykes, 2003; Ovidio et al., 2013; Itakura et al., 2017). Half of the eels were recaptured from the original section of capture (i.e., distance travelled $<10 \mathrm{~m}$ ), suggesting strong fidelity of growthphase A. marmorata to 'familiar' habitats, as mentioned for A. japonica (Itakura et al., 2017). Furthermore, the distance travelled of small eels was greater than that of large eels, which is likely related to the upstream or downstream dispersal behavior after recruitment as discussed above, while large eels show sedentary behavior after they establish a home range (Imbert et al., 2010; Wakiya, Kaifu \& Mochioka, 2016).

Because we performed the sampling during daytime only, the short distance travelled reported here was limited to their movement between daytime refuges. Considering that anguillid eels are generally nocturnal (Parker, 1995; Jellyman \& Sykes, 2003; Ovidio et al., 2013; Itakura et al., 2017), it is likely that growth-phase A. marmorata move longer distances during night than observations in this study have indicated. In addition, the sampling events were conducted only four times over the 2-year study period, which make it difficult to estimate more exact distances travelled of eels or the sizes of their home ranges. Therefore, a mark-recapture experiment with more intensive sampling during both daytime and night or more continuous studies using methods such as biotelemetry are needed to further understand the movement ecology of this species.

\section{Growth}

The direct measurement of individual growth by the mark-recapture experiment revealed that the A. marmorata in this river had a very wide range of annual GR among the 48 recaptured eels that ranged from 0 to $163.2 \mathrm{~mm} /$ year, with a mean $\pm \mathrm{SD}$ of $31.8 \pm 31.0 \mathrm{~mm} /$ year. This mean GR value is generally consistent with the otolith-based estimate value $(25.9 \pm 6.6 \mathrm{~mm} /$ year $)$ obtained from other rivers on same island (Wakiya, Itakura \& Kaifu, 2019). This indicates that otolithbased age estimates of this species in the previous study seem to be reasonable and that the otolith analysis method can be useful for the estimating age of $A$. marmorata. The range of GR from this study was much wider than the otolith-based estimate values (15.8-50.2 mm/year) from Wakiya, Itakura \& Kaifu, (2019). Surprisingly, some individuals showed no (zero) or very high ( $>100 \mathrm{~mm} / \mathrm{year})$ annual growth. Compared to our results, the mean GR of A. marmorata in an equatorial region (Sulawesi Island Indonesia) was three times higher than that in this study 
612 (Hagihara et al., 2018b). As discussed by Wakiya, Itakura \& Kaifu, (2019), the differences in GR 613 of the species among latitudinally different regions may partly be explained the differences in 614 annual water temperatures and productivity in the growth habitats. These results suggest that $A$. 615 marmorata may accommodate any growth situations including extreme low and high growth 616 conditions in response to a variety of environments. This diverse growth pattern of the species 617 might allow eels to adapt to various habitats in continental waters in latitudinally expanded 618 distributional regions from the equator to higher latitude regions such as southern Japan (Mizuno 619 \& Nagasawa, 2010).

620 In our study that extended across 2 years, there might have been seasonal and interannual 621 differences in temperature and food availability that could have affected the GR of eels during 622 each marked and recapture period that were of various durations, although study period was not 623 selected by the best model. Temperature is one of the main seasonal and interannual effects on 624 eel growth (Daverat et al., 2012; Yokouchi \& Daverat, 2013), but this may typically also be 625 linked to seasonal cycles of prey availability. Eels that were caught in July 2017 and recaptured 626 in September 2018 would have experienced an entire seasonal cycle in the river, and they had the highest GR among eels in this study. Conversely, eels that were caught in August 2016 and recaptured in November 2016 only experienced three months that did not include the spring season, and those eels had the lowest median GR and the highest range of GR values. Further research is required to examine the seasonal differences of growth of $A$. marmorata by conducting a mark-recapture experiment with seasonal intervals.

Another potential reason to explain the difference in GR of eels among the study periods is possible seasonal differences in food availability for the eels. Although we did not document the seasonal patterns of their species composition and abundance, a total of 33 diadromous fish and crustacean species was found in the study river during the sampling surveys, which are likely potential prey species for eels. In other rivers of the study island, the biomass of these fish and crustacean species accounted for more than $80 \%$ of stomach contents of $A$. marmorata (Wakiya et al., unpublished data). These diadromous species can have seasonal patterns of recruitment into rivers with their own phenology (Tanaka et al., 2020), so their recruitment dynamics might lead to seasonal and interannual differences in food availability in the river, which could affect the GR of eels. A greater diversity of fish and crustacean species and higher overall abundance appeared to be present in the lower river reaches below about $320 \mathrm{~m}$ from the river mouth (Table $\mathrm{S} 1$ ), which might be one reason why few eels were found in the more narrow upper reaches that likely have a lower carrying capacity for eels.

\section{Conclusions}

647 Our study is the first to provide information about several aspects of the riverine ecology of the 
648 spatial distribution, growth, and movement of the tropical eel A. marmorata in relation to 649 environmental conditions, because we conducted a mark-recapture experiment across 2 years 650 throughout the main reaches of the Oganeku River on Amami-Oshima Island, Japan, where it 651 was the highly dominant anguillid species compared to small numbers of Japanese eels. This 652 ecological information about $A$. marmorata in a small subtropical island river can be compared 653 to future studies in different regions and will contribute to conservation and management efforts 654 for anguillid eels in the Indo-Pacific.

655

\section{Acknowledgments}

657 We are deeply grateful to K. Ebihara, M. Gollock, K. Iwabuchi, K. Kaifu, M. Matsuoka, M. 658 Sakai for their help in the field sampling. H.I. was financially supported by a Research 659 Fellowship for Young Scientists and a Postdoctoral Fellowship for Research Abroad from the 660 Japan Society for Promotion of Science. This study was supported by the River Fund of the 661 River Foundation, Japan, the Sasakawa Scientific Research Grant from the Japan Science 662 Society, and the Environmental Research Fund of the Ministry of the Environment, Japan.

\section{References}

Aprahamian MW, Walker AM, Williams B, Bark A, Knights B. 2007. On the application of models of European eel (Anguilla anguilla) production and escapement to the development of Eel Management Plans: The River Severn. ICES Journal of Marine Science 64:14721482. DOI: $10.1093 /$ icesjms/fsm131.

Arai T, Abdul Kadir SR. 2017. Diversity, distribution and different habitat use among the tropical freshwater eels of genus Anguilla. Scientific Reports 7:7593. DOI: 10.1038/s41598017-07837-x.

Arai T, Chino N. 2018. Opportunistic migration and habitat use of the giant mottled eel Anguilla marmorata (Teleostei: Elopomorpha). Scientific Reports 8:5666. DOI: 10.1038/s41598018-24011-z.

Bartoń K. 2019.MuMIn: Multi-Model Inference. Available at https://CRAN.Rproject.org/package =MuMIn (accessed 22 June 2020).

Béguer-Pon M, Castonguay M, Benchetrit J, Hatin D, Legault M, Verreault G, Mailhot Y, Tremblay V, Dodson JJ. 2015. Large-scale, seasonal habitat use and movements of yellow American eels in the St. Lawrence River revealed by acoustic telemetry. Ecology of Freshwater Fish 24:99-111. DOI: 10.1111/eff.12129.

Bergmann J, Ryo M, Prati D, Hempel S, Rillig MC. 2017. Root traits are more than analogues of leaf traits: the case for diaspore mass. New Phytologist 216:1130-1139. DOI: 10.1111/nph.14748. 
684

685

686

687

688

689

690

691

692

693

694

695

696

697

698

699

700

701

702

703

704

705

706

707

708

709

710

711

712

713

714

715

716

717

718

719

Bischl B, Lang M, Kotthoff L, Schratz P, Schiffner J, Richter J, Jones Z, Casalicchio G, Gallo M, Bossek J, Studerus E, Judt L, Kuehn T, Kerschke P, Fendt F, Probst P, Sun X, Thomas J, Vieira B, Beggel L, Au Q, Binder M, Pfisterer F, Coors S, Bronder S, Engelhardt A, Molnar C, Spooner A. 2020. mlr: Machine Learning in R. Available at https://CRAN.Rproject.org/package $=\mathrm{mlr}$ (accessed 22 June 2020).

Breiman L. 1996. Out-of-bag estimation. Berkeley, CA.

Breiman LEO. 2001. Random Forests. Machine learning 45:5-32. DOI: doi.org/10.1023/A:101093340.

Costa JL, Domingos I, Assis CA, Almeida PR, Moreira F, Feunteun E, Costa MJ. 2008. Comparative ecology of the European eel, Anguilla anguilla (L., 1758), in a large Iberian river. Environmental Biology of Fishes 81:421-434. DOI: 10.1007/s10641-007-9229-2.

Daverat F, Beaulaton L, Poole R, Lambert P, Wickström H, Andersson J, Aprahamian M, Hizem B, Elie P, Yalçin-Özdilek S, Gumus A. 2012. One century of eel growth: Changes and implications. Ecology of Freshwater Fish 21:325-336. DOI: 10.1111/j.16000633.2011.00541.x.

Daverat F, Limburg KE, Thibault I, Shiao JC, Dodson JJ, Caron F, Tzeng WN, Iizuka Y, Wickström H. 2006. Phenotypic plasticity of habitat use by three temperate eel species, Anguilla anguilla, A. japonica and A. rostrata. Marine Ecology Progress Series 308:231241. DOI: $10.3354 /$ meps308231.

Daverat F, Tomás J. 2006. Tactics and demographic attributes in the European eel (Anguilla anguilla): the case study of the Gironde watershed (Southwest France). Marine Ecology Progress Series 307:247-257. DOI: 10.3354/meps307247.

Edeline E, Beaulaton L, Le Barh R, Elie P. 2007. Dispersal in metamorphosing juvenile eel Anguilla anguilla. Marine Ecology Progress Series 344:213-218. DOI: 10.3354/meps06988.

Ege V. 1939. A revision of the genus Anguilla Shaw: a systematic, phylogenetic and geographical study. Dana Report 16:1-256.

Glova GJ, Jellyman DJ, Bonnett ML. 1998. Factors associated with the distribution and habitat of eels (Anguilla spp.) in three New Zealand lowland streams. New Zealand Journal of Marine and Freshwater Research 32:255-269. DOI: 10.1080/00288330.1998.9516824.

Gollock M, Shiraishi H, Carrizo S, Crook V, Levy E. 2018. Status of non-CITES listed anguillid eels. CITES AC30 Document 18.1 Annex 2.

Gunning GE, Shoop CR. 1961. Restricted movements of the American eel, (Anguilla rostrata) (Le Sueur), in freshwater streams with comment on growth rate. Tulane Studies in Zoology 9:265-272.

Hagihara S, Aoyama J, Limbong D, Tsukamoto K. 2012. Morphological and physiological 
changes of female tropical eels, Anguilla celebesensis and Anguilla marmorata, in relation to downstream migration. Journal of Fish Biology 81:408-426. DOI: 10.1111/j.10958649.2012.03332.x.

Hagihara S, Aoyama J, Limbong D, Tsukamoto K. 2018a. Interspecific and sexual differences in riverine distribution of tropical eels Anguilla spp. Journal of Fish Biology 93:21-29. DOI: 10.1111/jfb.13666.

Hagihara S, Aoyama J, Limbong D, Tsukamoto K. 2018b. Age and growth of migrating tropical eels, Anguilla celebesensis and Anguilla marmorata. Journal of Fish Biology 92:15261544. DOI: $10.1111 / \mathrm{jfb} .13608$.

Hapfelmeier A, Ulm K. 2013. A new variable selection approach using Random Forests. Computational Statistics and Data Analysis 60:50-69. DOI: 10.1016/j.csda.2012.09.020.

Haro AJ, Krueger WH. 1991. Pigmentation, otolith rings, and upstream migration of juvenile American eels (Anguilla rostrata) in a coastal Rhode Island stream. Canadian Journal of Zoology 69:812-814. DOI: 10.1139/z91-120.

Hsu HY, Chen HW, Han YS. 2019. Habitat partitioning and its possible genetic background between two sympatrically distributed eel species in Taiwan. Zoological Studies 58:27. DOI: 10.6620/ZS.2019.58-27.

Ibbotson A, Smith J, Scarlett P, Aprhamian M. 2002. Colonisation of freshwater habitats by the European eel Anguilla anguilla. Freshwater Biology 47:1696-1706. DOI: 10.1046/j.13652427.2002.00930.x.

Imbert H, Labonne J, Rigaud C, Lambert P. 2010. Resident and migratory tactics in freshwater European eels are size-dependent. Freshwater Biology 55:1483-1493. DOI: 10.1111/j.1365-2427.2009.02360.x.

Itakura H, Kaino T, Miyake Y, Kitagawa T, Kimura S. 2015. Feeding, condition, and abundance of Japanese eels from natural and revetment habitats in the Tone River, Japan. Environmental Biology of Fishes 98:1871-1888. DOI: 10.1007/s10641-015-0404-6.

Itakura H, Miyake Y, Kitagawa T, Kimura S. 2017. Site fidelity, diel and seasonal activities of yellow-phase Japanese eels (Anguilla japonica) in a freshwater habitat as inferred from acoustic telemetry. Ecology of Freshwater Fish:1-15. DOI: 10.1111/eff.12389.

Itakura H, Wakiya R, Gollock M, Kaifu K. 2020a. Anguillid eels as a surrogate species for conservation of freshwater biodiversity in Japan. Scientific reports. DOI: 10.1038/s41598020-65883-4z.

Itakura H, Wakiya R, Sakata MK, Hsu HY, Chen SC, Yang CC, Huang YC, Han YS, Yamamoto S, Minamoto T. 2020b. Estimations of Riverine Distribution, Abundance, and Biomass of Anguillid Eels in Japan and Taiwan Using Environmental DNA Analysis. Zoological Studies 59:17. DOI: 10.6620/ZS.2020.59-17. 
756

757

758

Itakura H, Wakiya R, Yamamoto S, Kaifu K, Sato T, Minamoto T. 2019. Environmental DNA analysis reveals the spatial distribution, abundance, and biomass of Japanese eels at the river-basin scale. Aquatic Conservation: Marine and Freshwater Ecosystems 29:361-373. DOI: $10.1002 /$ aqc.3058.

IUCN. 2019. The IUCN Red List of Threatened Species. Version 2019.2.

Jacoby DMP, Casselman JM, Crook V, DeLucia MB, Ahn H, Kaifu K, Kurwie T, Sasal P, Silfvergrip AMC, Smith KG, Uchida K, Walker AM, Gollock MJ. 2015. Synergistic patterns of threat and the challenges facing global anguillid eel conservation. Global Ecology and Conservation 4:321-333. DOI: 10.1016/j.gecco.2015.07.009.

Jacoby D, Gollock MJ. 2014. Anguilla marmorata. The IUCN Red List of Threatened Species 2014:e.T166189A45832585.

Jellyman DJ, Sykes JRE. 2003. Diel and seasonal movements of radio-tagged freshwater eels, Anguilla spp., in two New Zealand streams. Environmental Biology of Fishes 66:143-154. DOI: 10.1023/A:1023691604088.

Jessop BM, Shiao JC, lizuka Y, Tzeng WN. 2002. Migratory behaviour and habitat use by American eels Anguilla rostrata as revealed by otolith microchemistry. Marine Ecology Progress Series 233:217-229. DOI: 10.3354/meps233217.

Johnson JH, Nack CC. 2013. Habitat use of American eel (Anguilla rostrata) in a tributary of the Hudson River, New York. Journal of Applied Ichthyology 29:1073-1079. DOI: 10.1111/jai.12253.

Kaifu K, Tamura M, Aoyama J, Tsukamoto K. 2010. Dispersal of yellow phase Japanese eels Anguilla japonica after recruitment in the Kojima Bay-Asahi river system, Japan. Environmental Biology of Fishes 88:273-282. DOI: 10.1007/s10641-010-9640-y.

Kuhn M, Wing J, Weston S, Williams A, Keefer C, Engelhardt A, Cooper T, Mayer Z, Kenkel B, Team RC, Benesty M, Lescarbeau R, Ziem A, Scrucca L, Tang Y, Candan C, Hunt T. 2020. caret: Classification and Regression Training. Available at https://github.com/topepo/caret/ (accessed 22 June 2020).

Kumai Y, Tsukamoto K, Kuroki M. 2020. Growth and habitat use of two anguillid eels, Anguilla marmorata and A. japonica, on Yakushima Island, Japan. Ichthyological Research. DOI: 10.1007/s10228-020-00732-y.

Kume M, Terashima Y, Kawai F, Kutzer A, Wada T, Yamashita Y. 2020. Size-dependent changes in habitat use of Japanese eel Anguilla japonica during the river life stage.

Kume M, Terashima Y, Wada T, Yamashita Y. 2019. Longitudinal distribution and microhabitat use of young Japanese eel Anguilla japonica in a small river flowing through paddy areas. Journal of Applied Ichthyology 35:876-883. DOI: 10.1111/jai.13911.

Kuroki M, Aoyama J, Miller MJ, Yoshinaga T, Shinoda A, Hagihara S, Tsukamoto K. 2009. 
792

793

794

795

796

797

798

799

800

801

802

803

804

805

806

807

808

809

810

811

812

813

814

815

816

817

818

819

820

821

822

823

824

825

826

827

Sympatric spawning of Anguilla marmorata and Anguilla japonica in the western North Pacific Ocean. Journal of Fish Biology 74:1853-1865. DOI: 10.1111/j.10958649.2009.02299.x.

Laffaille P, Acou A, Guillouët J. 2005. The yellow European eel (Anguilla anguilla L.) may adopt a sedentary lifestyle in inland freshwaters. Ecology of Freshwater Fish 14:191-196. DOI: 10.1111/j.1600-0633.2005.00092.x.

Laffaille P, Feunteun E, Baisez A, Robinet T, Acou A, Legault A, Lek S. 2003. Spatial organisation of European eel (Anguilla anguilla) in a small catchment. Ecology of Freshwater Fish 12: 254-264.

Marquet G, Galzin R. 1991. The eels of French Polynesia: Taxonomy, distribution and biomass. La mer 29:8-17.

Minegishi Y, Aoyama J, Tsukamoto K. 2008. Multiple population structure of the giant mottled eel, Anguilla marmorata. Molecular Ecology 17:3109-3122. DOI: 10.1111/j.1365294X.2008.03822.x.

Ministry of Environment. 2016. Report of consultation business for conservation policy of the Japanese eel.

Mizuno K, Nagasawa K. 2010. Occurrence and habitats of the giant mottled eel Anguilla marmorata (Anguilliformes, Anguillidae) in rivers of Ehime Prefecture, Japan. Biogeography 12:133-139.

Moriarty C. 2003. The yellow eel. In: Aida K, Tsukamoto K, Yamauchi K eds. Eel biology. Tokyo, Japan: Springer, 89-105.

Morrison WE, Secor DH. 2003. Demographic attributes of yellow-phase American eels (Anguilla rostrata) in the Hudson River estuary. Canadian Journal of Fisheries and Aquatic Sciences 60:1487-1501.

Nguyen AT, Tsukamoto K, Lokman PM. 2018. Composition and distribution of freshwater eels Anguilla spp. in Vietnam. Fisheries Science 84:987-994. DOI: 10.1007/s12562-018-12399.

Nicodemus KK, Malley JD, Strobl C, Ziegler A. 2010. The behaviour of random forest permutation-based variable importance measures under predictor correlation. $B M C$ Bioinformatics 11:110. DOI: 10.1186/1471-2105-11-110.

Okamura A, Yamada Y, Yokouchi K, Horie N, Mikawa N, Utoh T, Tanaka S, Tsukamoto K. 2007. A silvering index for the Japanese eel Anguilla japonica. Environmental Biology of Fishes 80:77-89. DOI: 10.1007/s10641-006-9121-5.

Ovidio M, Seredynski AL, Philippart JC, Nzau Matondo B. 2013. A bit of quiet between the migrations: The resting life of the European eel during their freshwater growth phase in a small stream. Aquatic Ecology 47:291-301. DOI: 10.1007/s10452-013-9444-1. 
Parker SJ. 1995. Homing Ability and Home Range of Yellow-Phase American Eels in a Tidally Dominated Estuary. Journal of the Marine Biological Association of the United Kingdom 75:127-140. DOI: 10.1017/S0025315400015241.

Robinet T, Feunteun E, Keith P, Marquet G, Olivier JM, Réveillac E, Valade P. 2007. Eel community structure, fluvial recruitment of Anguilla marmorata and indication for a weak local production of spawners from rivers of Réunion and Mauritius islands. Environmental Biology of Fishes 78:93-105. DOI: 10.1007/s10641-006-9042-3.

Ryo M, Harvey E, Robinson CT, Altermatt F. 2018. Nonlinear higher order abiotic interactions explain riverine biodiversity. Journal of Biogeography 45:628-639. DOI: 10.1111/jbi.13164.

Shiao JC, lizuka Y, Chang CW, Tzeng WN. 2003. Disparities in habitat use and migratory behavior between tropical eel Anguilla marmorata and temperate eel A. japonica in four Taiwanese rivers. Marine Ecology Progress Series 261:233-242. DOI: $10.3354 /$ meps 261233.

Smogor RA, Angermeier PL, Gaylord CK. 1995. Distribution and Abundance of American Eels in Virginia Streams: Tests of Null Models across Spatial Scales. Transactions of the American Fisheries Society 124:789-803. DOI: 10.1577/1548-8659(1995)124<0789.

Strobl C, Boulesteix AL, Kneib T, Augustin T, Zeileis A. 2008. Conditional variable importance for random forests. DOI: 10.1186/1471-2105-9-307.

Strobl C, Hothorn T, Zeileis A. 2009. Party on! A new, conditional variable importance measure available in the party package. The R Journal:14-17.

Tanaka R, Hirashima K, Kunishima T, Uno H, Sato T. 2020. Phenological diversity of freshwater migration can prolong assemblage-level migration period in amphidromous fishes in a temperate river system in Japan. Ecological Research:1-10. DOI: 10.1111/14401703.12132.

Taniguchi Y, Inoue M, Kawaguchi Y. 2001. Stream fish habitat science and management in Japan: a review. Aquatic Ecosystem Health and Management 4:357-365. DOI: 10.1080/146349801317276035.

Tsukamoto K, Chow S, Otake T, Kurogi H, Mochioka N, Miller MJ, Aoyama J, Kimura S, Watanabe S, Yoshinaga T, Shinoda A, Kuroki M, Oya M, Watanabe T, Hata K, Ijiri S, Kazeto Y, Nomura K, Tanaka H. 2011. Oceanic spawning ecology of freshwater eels in the western North Pacific. Nature communications 2:179. DOI: 10.1038/ncomms1174.

Vøllestad LA. 1992. Geographic Variation in Age and Length at Metamorphosis of Maturing European Eel : Environmental Effects and Phenotypic Plasticity. Journal of Animal Ecology $61: 41-48$.

Vøllestad LA, Jonsson B. 1988. A 13-Year Study of the Population Dynamics and Growth of the 
European Eel Anguilla anguilla in a Norwegian River : Evidence for Density-Dependent Mortality, and Development of a Model for Predicting Yield. jour 57:983-997.

Walker AM, Godard MJ, Davison P. 2014. The home range and behaviour of yellow-stage European eel Anguilla anguilla in an estuarine environment. Aquatic Conservation: Marine and Freshwater Ecosystems 24:155-165. DOI: 10.1002/aqc.2380.

Wakiya R, Itakura H, Kaifu K. 2019. Age, growth, and sex ratios of the giant mottled eel, Anguilla marmorata, in freshwater habitats near its northern geographic limit: a comparison to tropical regions. Zoological Studies 58:34. DOI: 10.6620/ZS.2019.58-34.

Wakiya R, Kaifu K, Azechi K, Tsukamoto K, Mochioka N. 2019. Evaluation of downward movements of Japanese eel Anguilla japonica inhabiting brackish water areas. Journal of Fish Biology:516-526. DOI: 10.1111/jfb.14236.

Wakiya R, Kaifu K, Mochioka N. 2016. Growth conditions after recruitment determine residence - emigration tactics of female Japanese eels Anguilla japonica. Fisheries Science 82:729736. DOI: $10.1007 / \mathrm{s} 12562-016-1006-8$.

Watanabe S, Aoyama J, Tsukamoto K. 2004. Reexamination of Eges (1939) Use of Taxonomic Characters of the Genus Anguilla. Bulletin of Marine Science 74:337-351.

Wolter C. 2001. Conservation of fish species diversity in navigable waterways. Landscape and Urban Planning 53:135-144. DOI: 10.1016/S0169-2046(00)00147-X.

Wood SN. 2019.mgcv: Mixed GAM Computation Vehicle with Automatic Smoothness Estimation

Yokouchi K, Aoyama J, Oka HP, Tsukamoto K. 2008. Variation in the demographic characteristics of yellow-phase Japanese eels in different habitats of the Hamana Lake system, Japan. Ecology of Freshwater Fish 17:639-652. DOI: 10.1111/j.16000633.2008.00315.x.

Yokouchi K, Daverat F. 2013. Modeling individual growth trajectories of the female European eel in relation to temperature and habitat-use history in the Gironde River, France. Aquatic Biology 19:185-193. DOI: 10.3354/ab00526.

Yokouchi K, Fukuda N, Miller MJ, Aoyama J, Daverat F, Tsukamoto K. 2012. Influences of early habitat use on the migratory plasticity and demography of Japanese eels in central Japan. Estuarine, Coastal and Shelf Science 107:132-140. DOI: 10.1016/j.ecss.2012.05.009.

\section{Figure caption}

Figure 1 Locations of Amami-Oshima Island, Japan and the Oganeku River. The study on giant mottled eels Anguilla marmorata was conducted during 4 sampling periods throughout the entire river drainage. 
901 Figure 2 Photographs of representative study sections of the Oganeku River. (A) $50 \mathrm{~m}$, (B) $90260 \mathrm{~m}$, (C) $130 \mathrm{~m}$, (D) $170 \mathrm{~m}$, (E) $230 \mathrm{~m}$, (F) $290 \mathrm{~m}$, (G) $310 \mathrm{~m}$, (H) $440 \mathrm{~m}$ sections from the river 903 mouth. The greatest number of large eels $(n=19)$ was collected at boulder riverbank habitat in the

904

905

906

907

908

909

910

911

912

913

914

915

916

917

918

919

920

921

922

923

924

925

926

927

928

929

930

931

932

933

934

935 section $60 \mathrm{~m}$ from the river mouth. Eels burrowed in boulder and vegetated riverbanks in the photos with some eels also burrowing in gaps in concrete riverbank. Moreover, large eels appeared to burrow under boulder or rocks, while small eels seemed to burrow in gravel.

Figure 3 Total lengths (TL) frequency histogram of $A$. marmorata eels collected in the Oganeku River. TL of $A$. marmorata was separated into the 2 general size groups of large and small eels.

Figure 4 Distributions of (A) sediment, (B) riverbank types, and (C) individual Total lengths (TL) of $\boldsymbol{A}$. marmorata eels in relation to distance from the river mouth in the Oganeku River. The line and shaded area in the right panel indicate the predictive value and $95 \%$ intervals of the generalized additive model, respectively. The open circles in the right panel show the capture locations and sizes of the 7 Japanese eels, A. japonica, that were captured during the surveys. TL of $A$. marmorata was separated into the 2 general size groups of large and small eels.

Figure 5 Relative importance scores of all predictor variables for density of $\boldsymbol{A}$. marmorata in the Oganeku River. The blue and grey bars indicate finally selected or not selected by the random forest models as a significant importance variable, respectively.

Figure 6 Modelled relationships of selected predictor variables by the random forest models for density of $\boldsymbol{A}$. marmorata in the Oganeku River. (A) Distance from the river mouth, (B) Riverbank type, (C) Depth (small eels), (D) Velocity (small eels). C, concrete.

Figure 7 Density of $\boldsymbol{A}$. marmorata for each environmental variable in the Oganeku River. (A) Depth, (B) Velocity, (C) Sediment type, and (D) Riverbank type. In the boxplots, the middle lines indicate the median, the boxes represent the 0.25 and 0.75 quartiles, the whiskers are the values that are within 1.5 of the interquartile range, and the dots show outliers.

Figure 8 Movement and growth patterns of recaptured $A$. marmorata in the Oganeku River. (A) Capture and recapture locations during each sampling survey connected by lines for each eel. (B) Histogram of distance travelled of the recaptured eels. (C) Histogram of the annual growth rates of the eels. 


\section{Figure 1}

Locations of Amami-Oshima Island, Japan and the Oganeku River.

The study on giant mottled eels Anguilla marmorata was conducted during 4 sampling periods throughout the entire river drainage. 


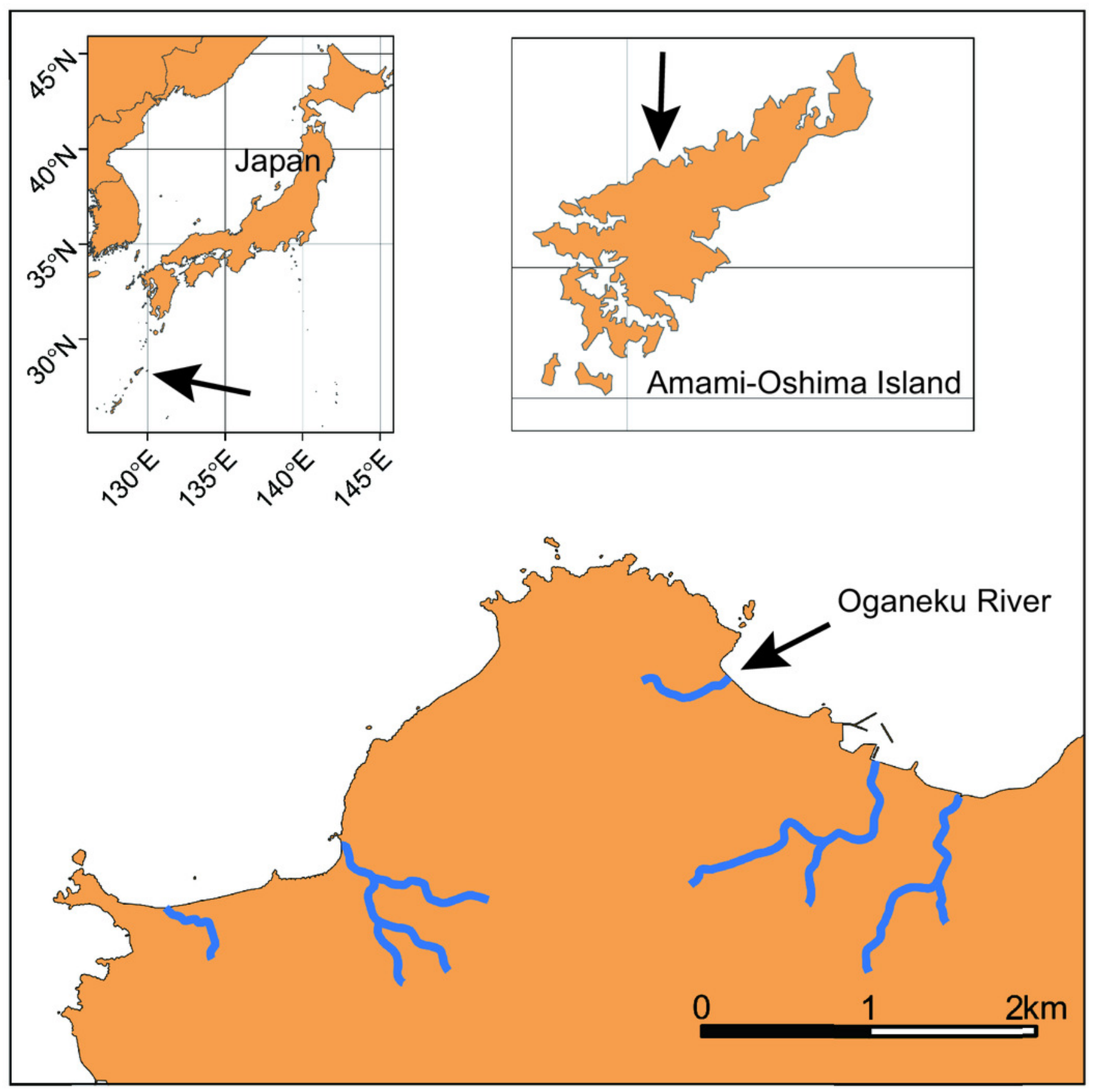




\section{Figure 2}

Photographs of representative study sections of the Oganeku River.
(A) $50 \mathrm{~m},(\mathrm{~B}) 60$
$m,(C) 130$
$m,(D) 170$
$m,(E) 230$
m, (F) 290
$m,(G) 310 m,(H) 440 m$

sections from the river mouth. The greatest number of large eels $(n=19)$ was collected at boulder riverbank habitat in the section $60 \mathrm{~m}$ from the river mouth. Eels burrowed in boulder and vegetated riverbanks in the photos with some eels also burrowing in gaps in concrete riverbank. Moreover, large eels appeared to burrow under boulder or rocks, while small eels seemed to burrow in gravel. 

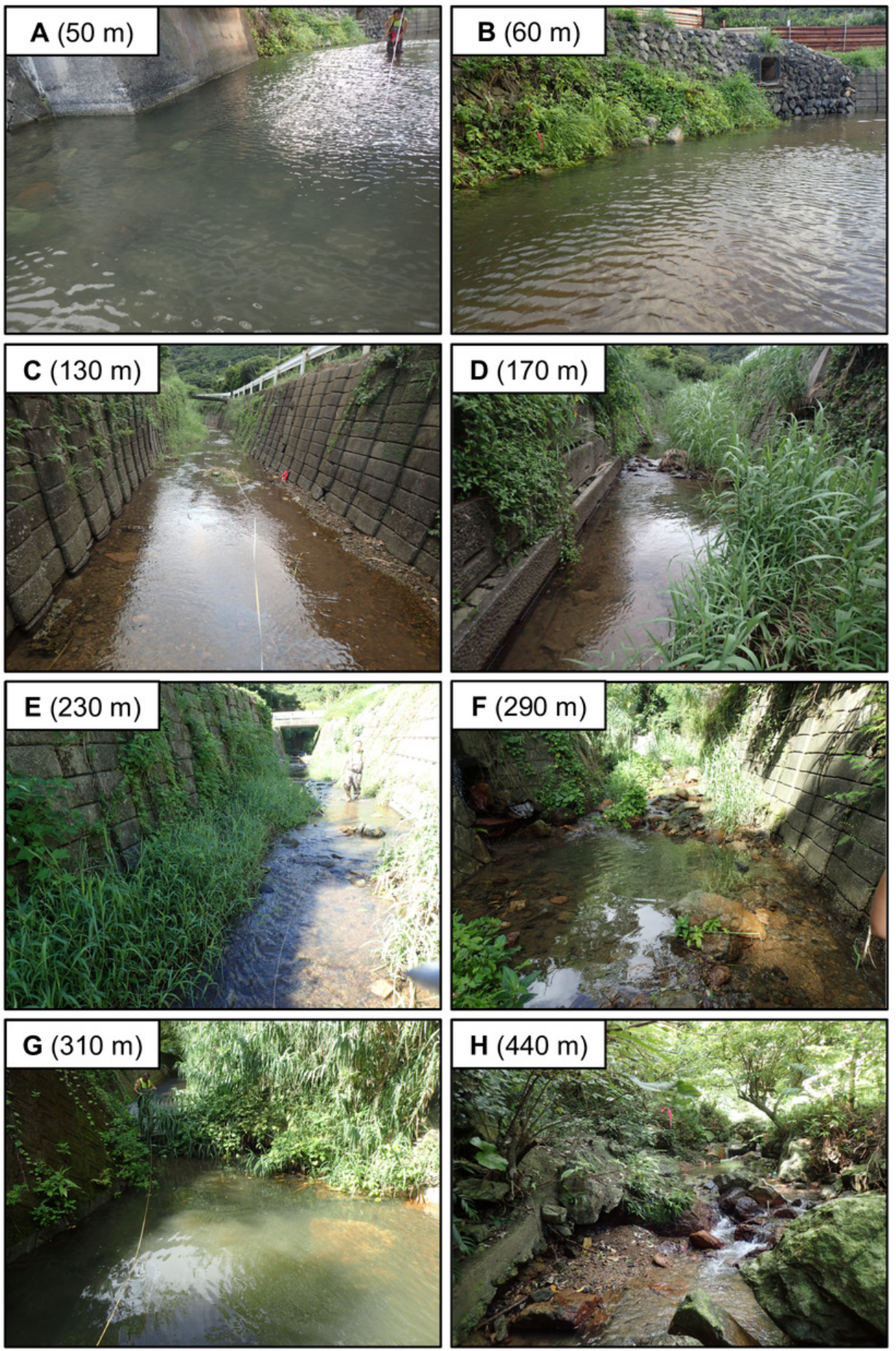
Figure 3

Total lengths (TL) frequency histogram of $A$. marmorata eels collected in the Oganeku River.

TL of A. marmorata was separated into the 2 general size groups of large and small eels.

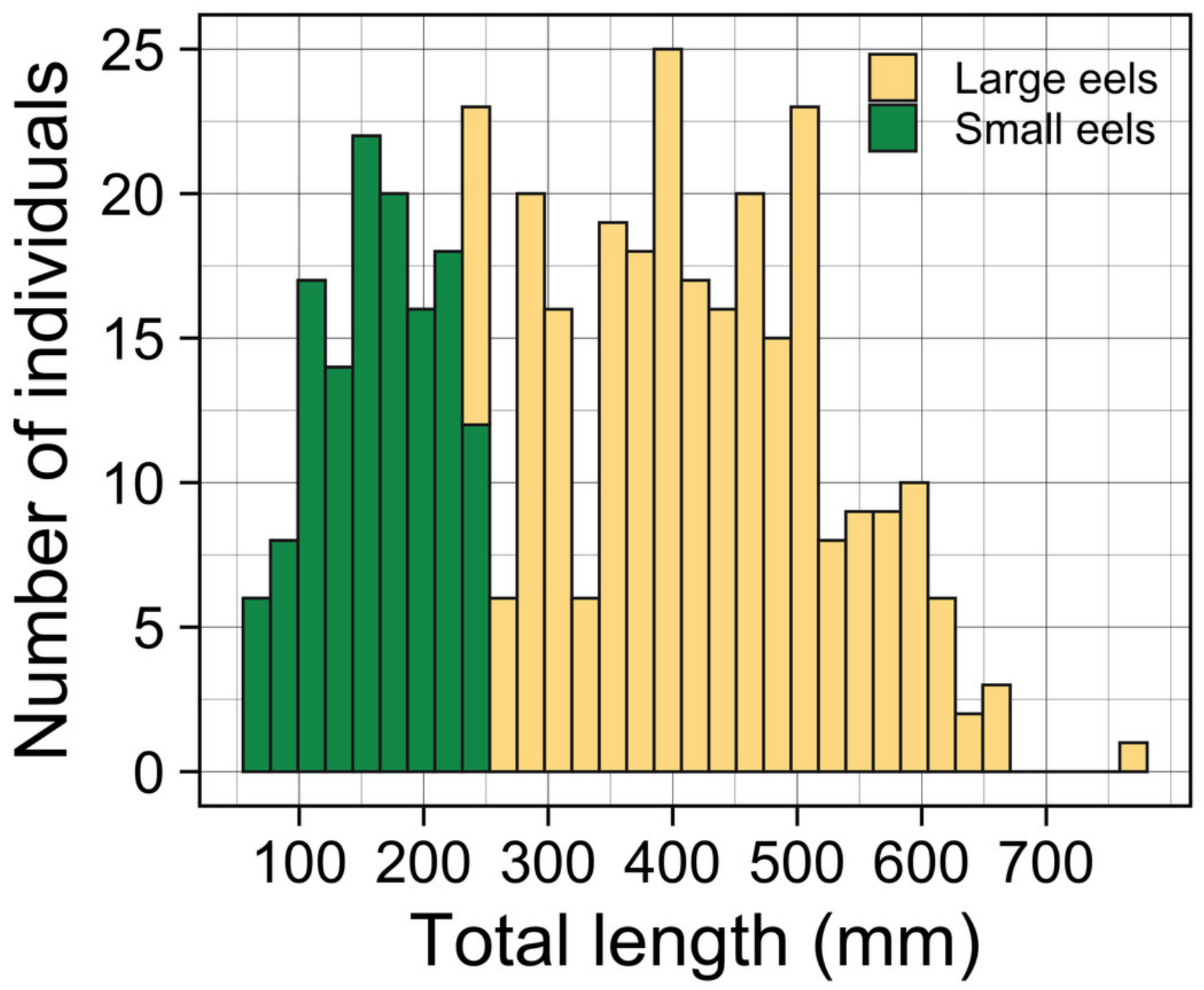




\section{Figure 4}

Distributions of (A) sediment, (B) riverbank types, and (C) individual Total lengths (TL) of A. marmorata eels in relation to distance from the river mouth in the Oganeku River.

The line and shaded area in the right panel indicate the predictive value and $95 \%$ intervals of the generalized additive model, respectively. The open circles in the right panel show the capture locations and sizes of the 7 Japanese eels, $A$. japonica, that were captured during the surveys. TL of $A$. marmorata was separated into the 2 general size groups of large and small eels. 


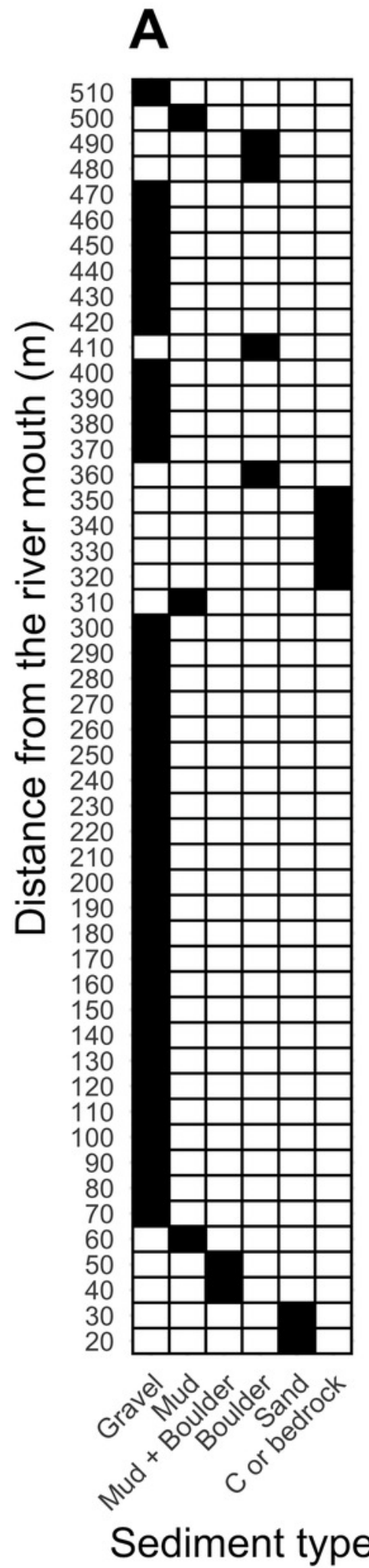

B

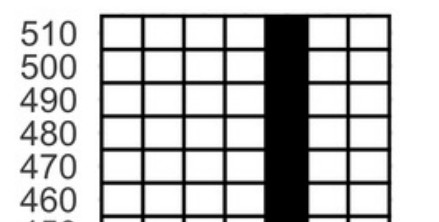

450

440

430

410

400

390

380

370

360

340

330

320

310

300

290

280

270

260

250

240

230

210

200

190

180

170

160

150

140

130

120

110

100

90

80
70

60

50

40

30

20

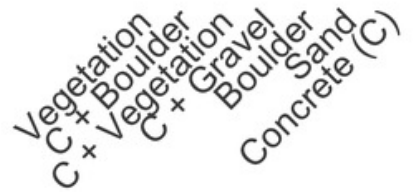

Riverbank type
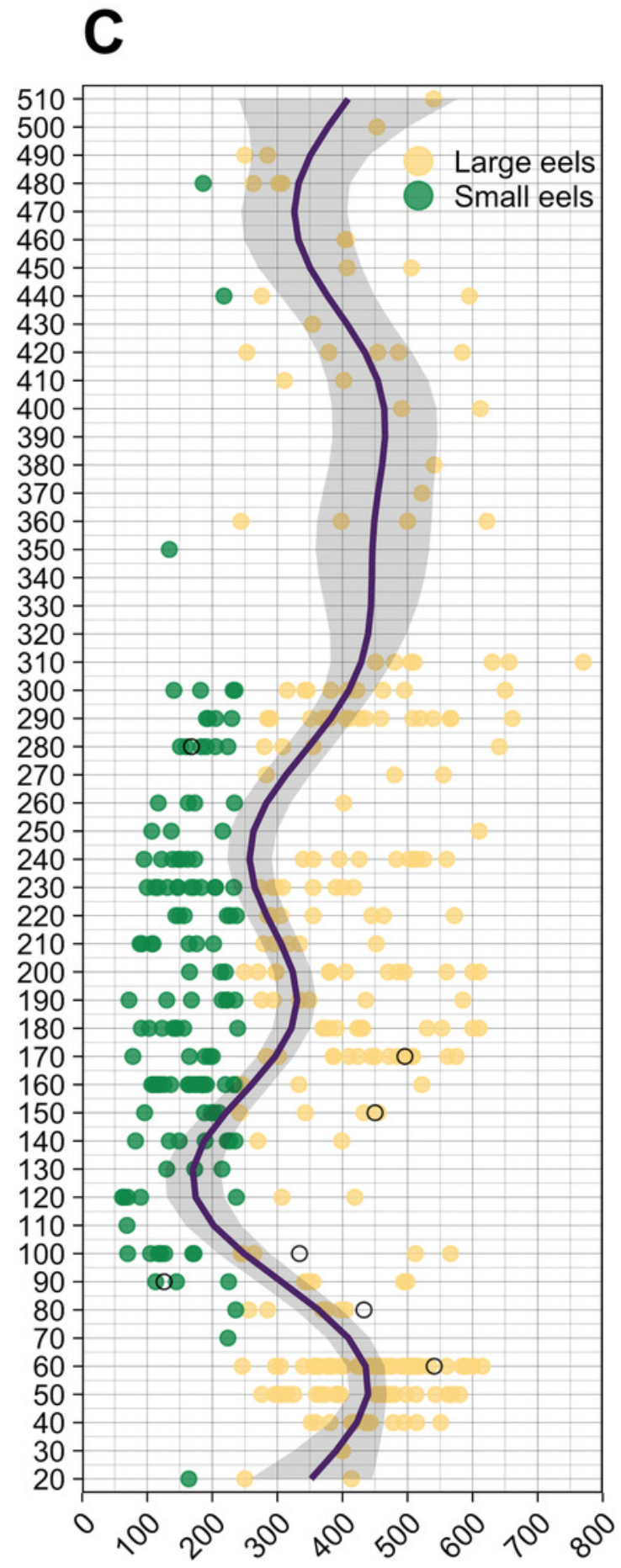

Total length $(\mathrm{mm})$ 
Figure 5

Relative importance scores of all predictor variables for density of $A$. marmorata in the Oganeku River.

The blue and grey bars indicate finally selected or not selected by the random forest models as a significant importance variable, respectively.

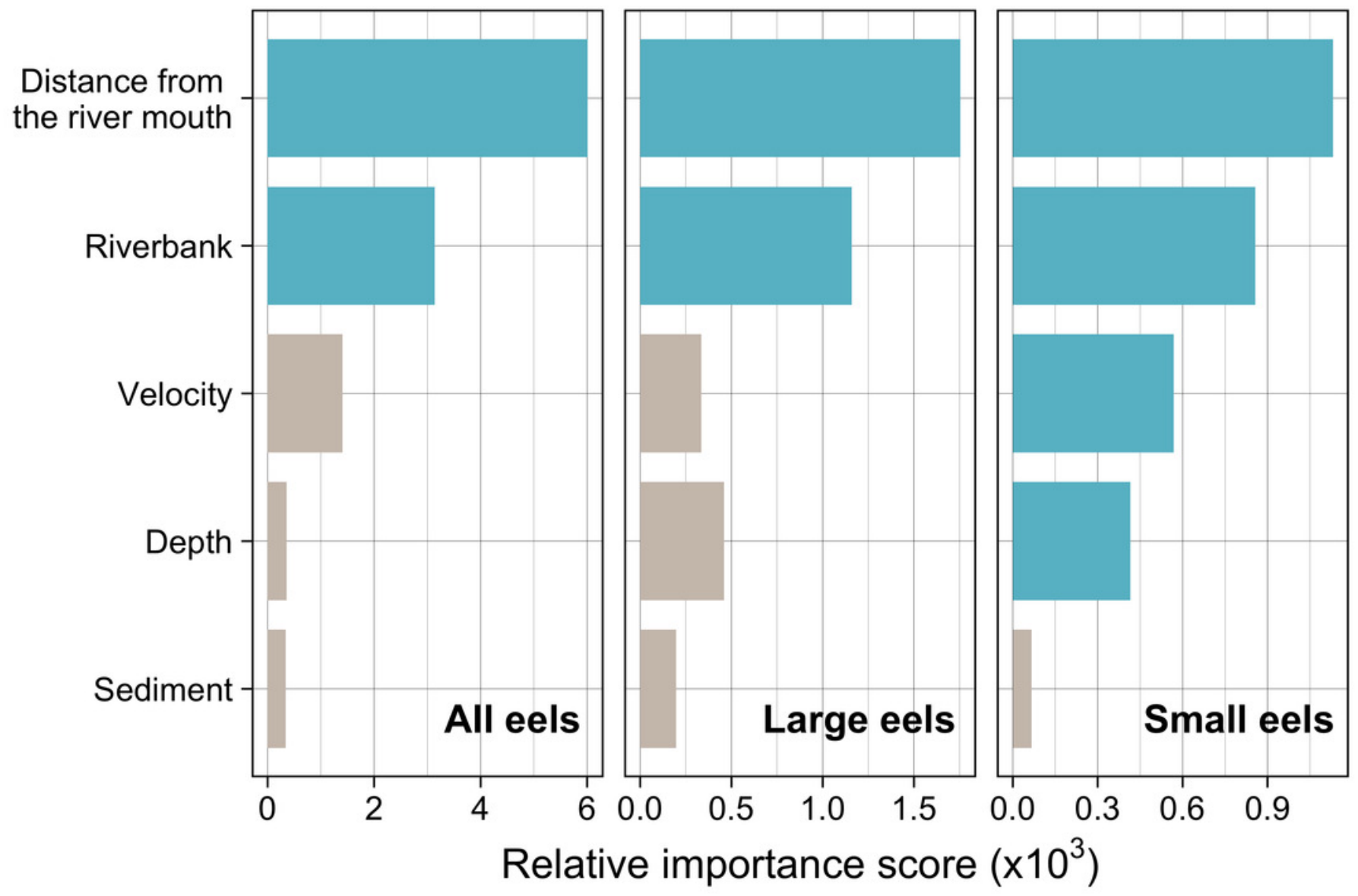


Figure 6

Modelled relationships of selected predictor variables by the random forest models for density of $A$. marmorata in the Oganeku River.

(A) Distance from the river mouth, (B) Riverbank type, (C) Depth (small eels), (D) Velocity (small eels). C, concrete. 


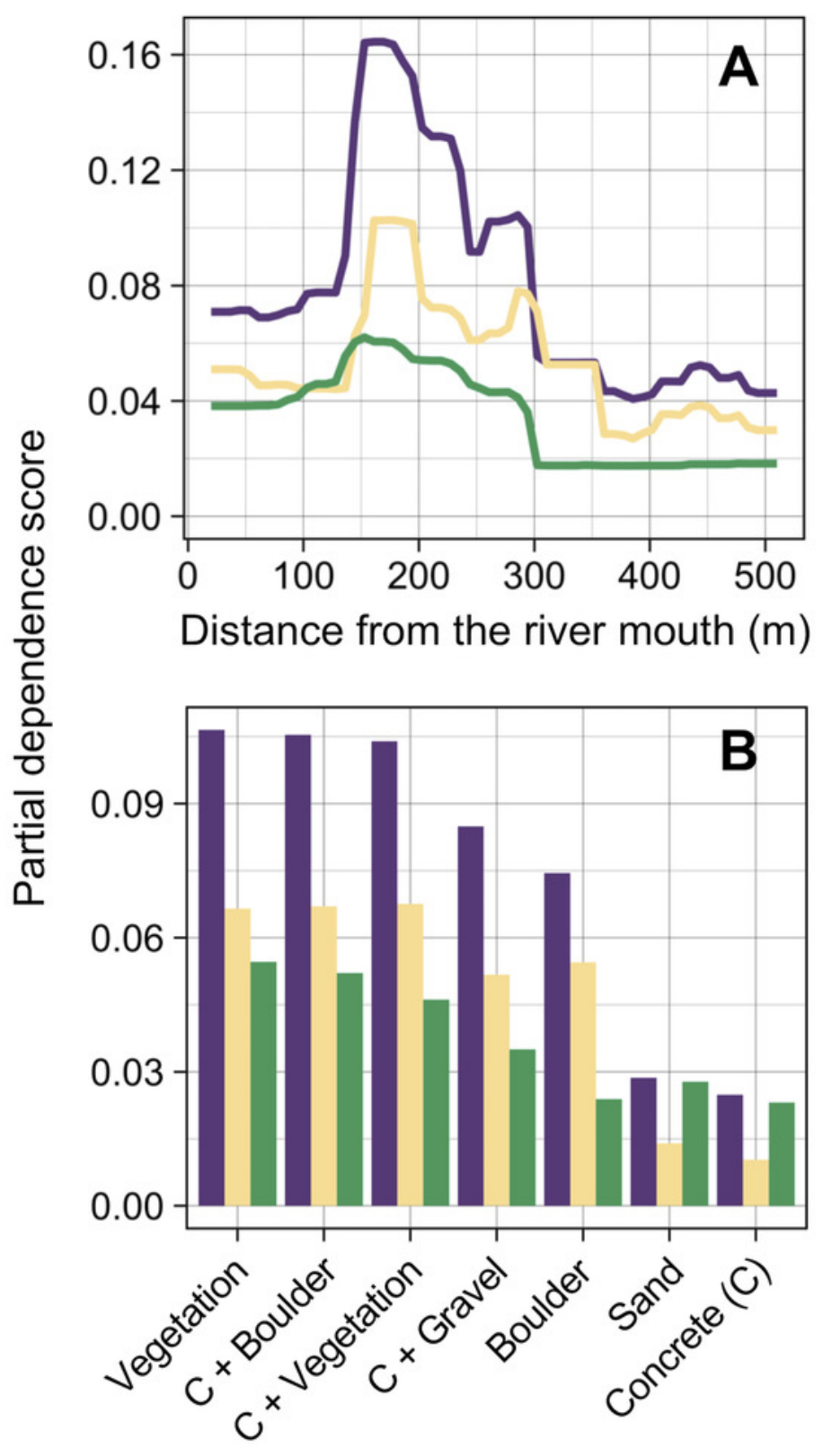

Riverbank type
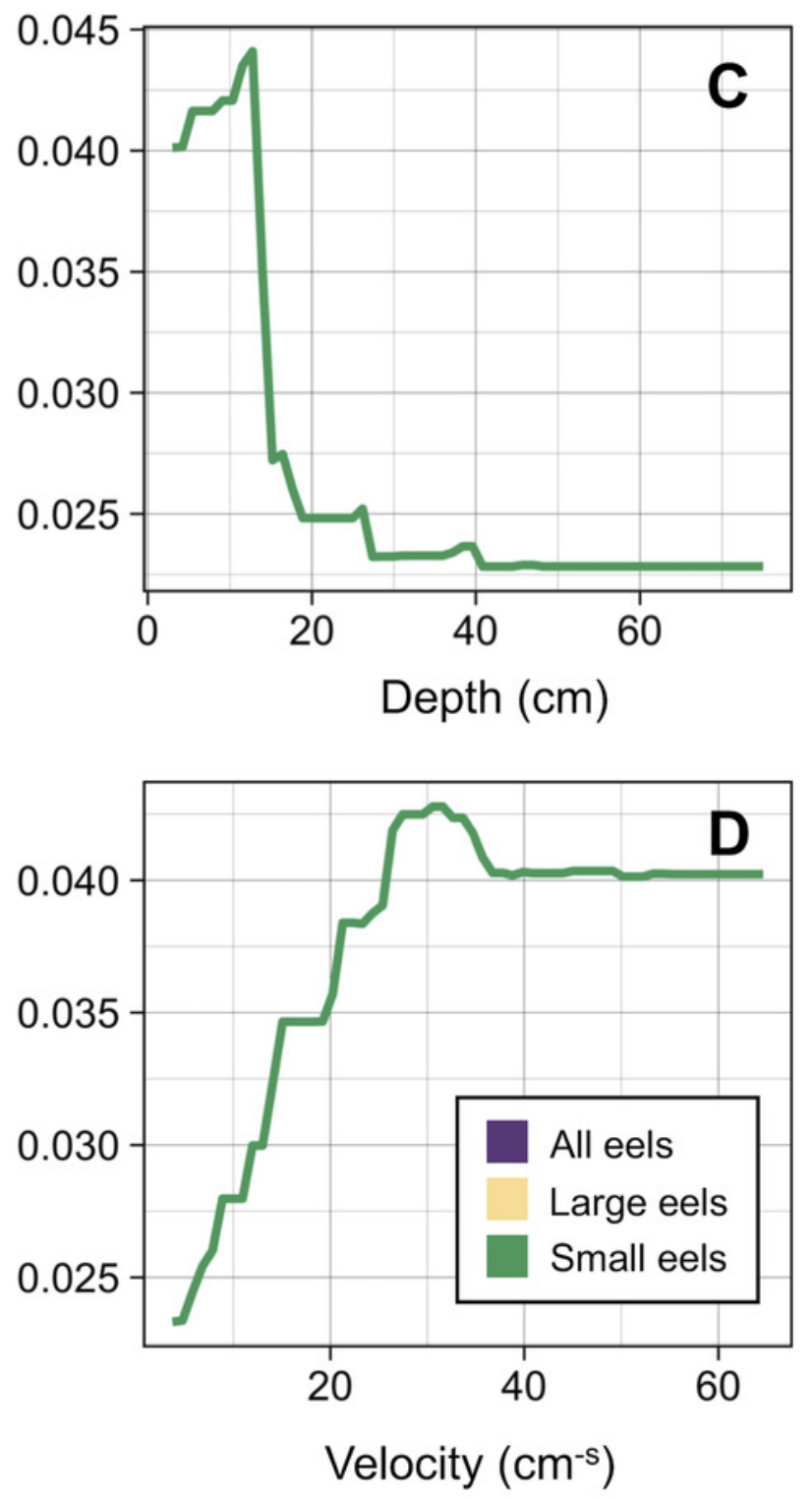


\section{Figure 7}

Density of $A$. marmorata for each environmental variable in the Oganeku River.

(A) Depth, (B) Velocity, (C) Sediment type, and (D) Riverbank type. In the boxplots, the middle lines indicate the median, the boxes represent the 0.25 and 0.75 quartiles, the whiskers are the values that are within 1.5 of the interquartile range, and the dots show outliers. 

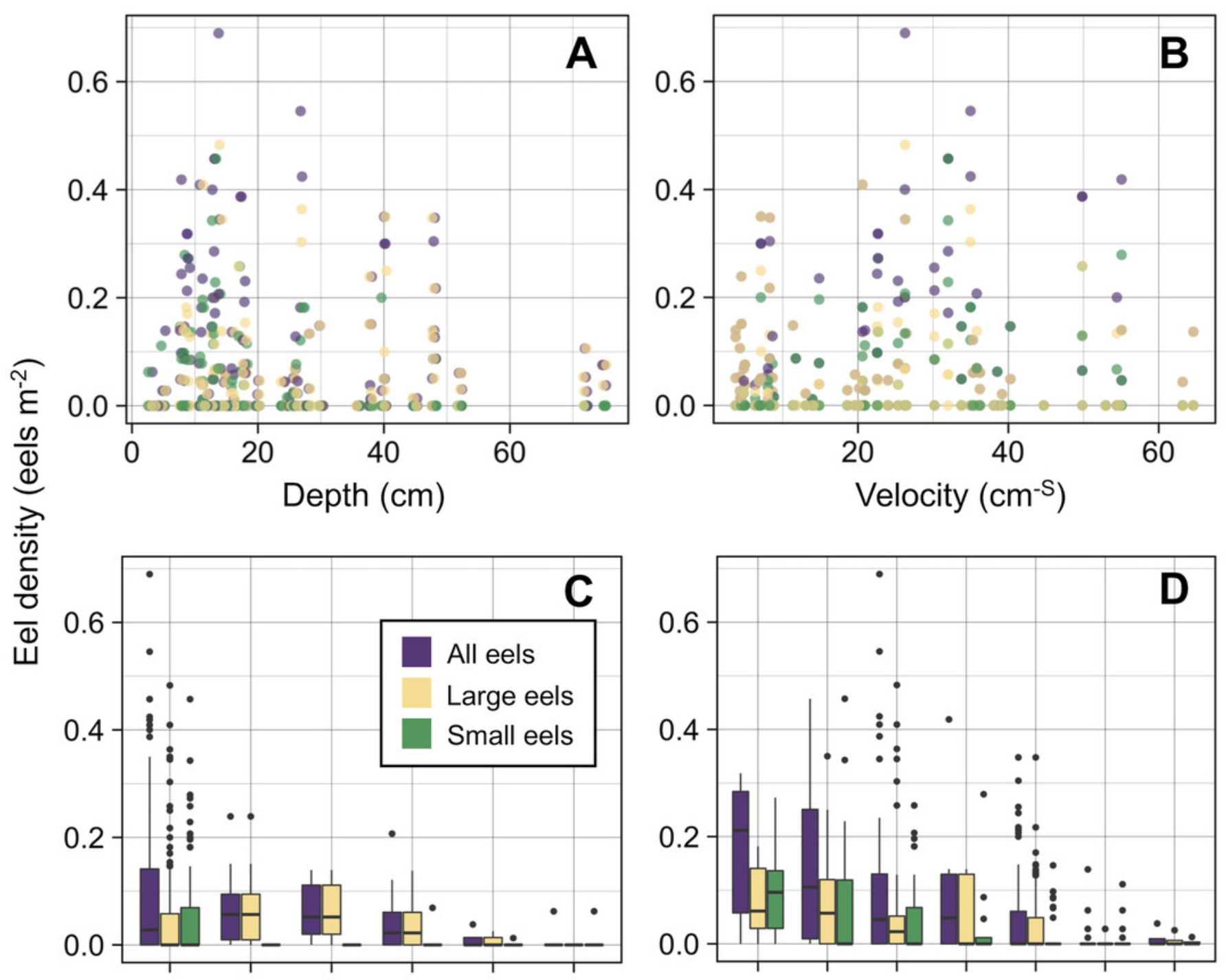

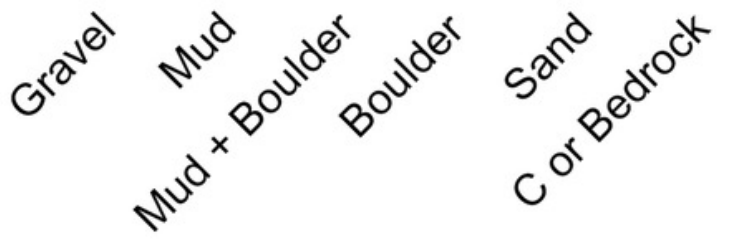

Sediment type

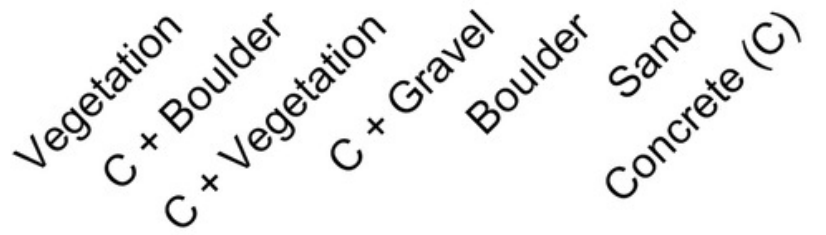

Riverbank type 
Figure 8

Movement and growth patterns of recaptured A. marmorata in the Oganeku River.

(A) Capture and recapture locations during each sampling survey connected by lines for each eel. (B) Histogram of distance travelled of the recaptured eels. (C) Histogram of the annual growth rates of the eels.
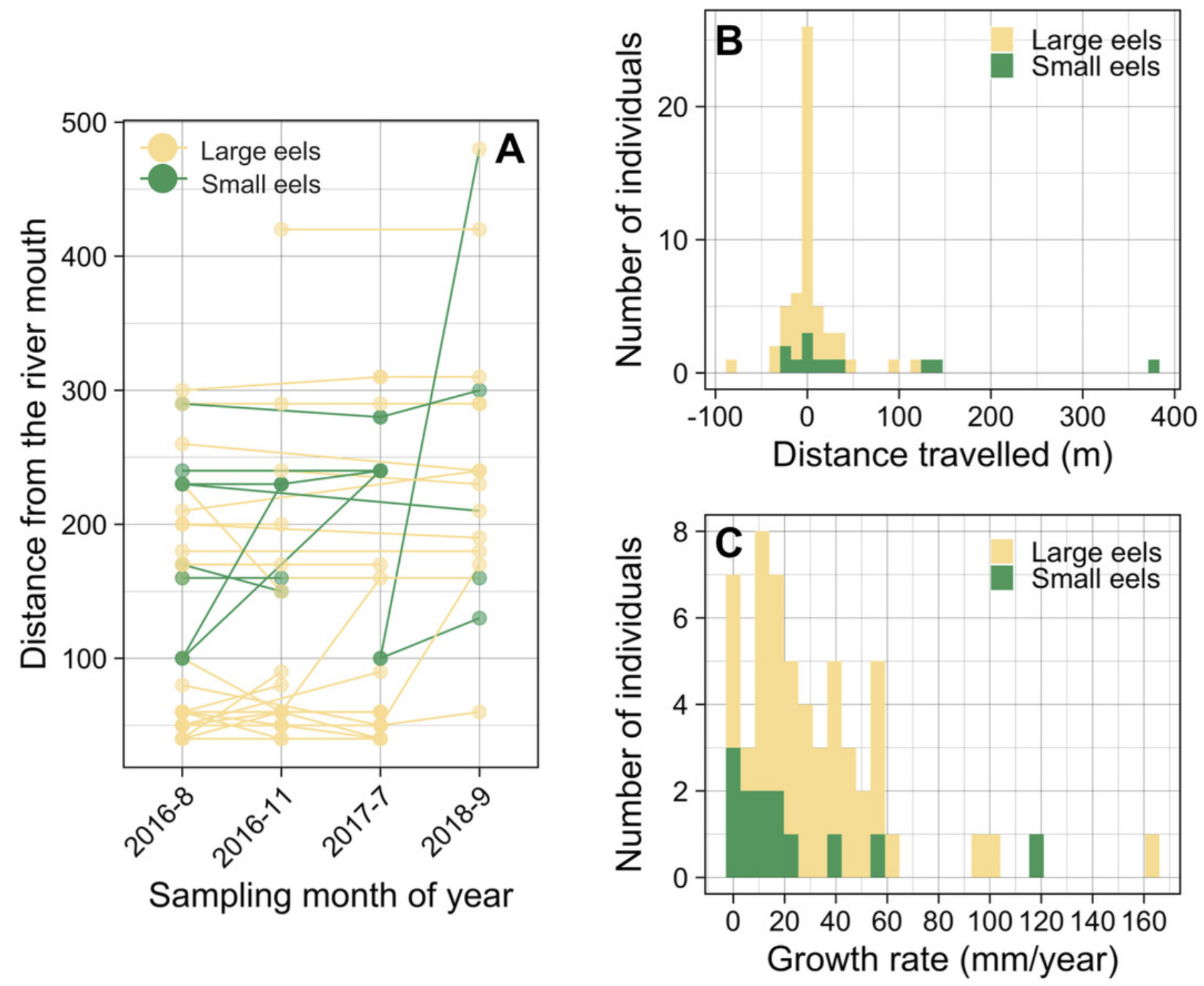